
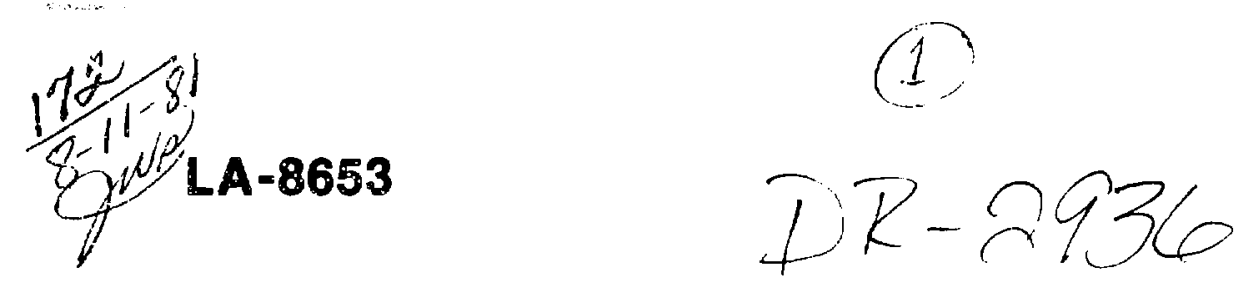

86311

A

Jifin

\title{
Automated Controlled-Potential Coulometer for Plutonium Determination
}




\title{
Automated Controlled-Potential Coulometer for Plutonium Determination
}

\author{
R. M. Hollen \\ D. D. Jackson
}




\section{CONTENTS}

ABSTRACT

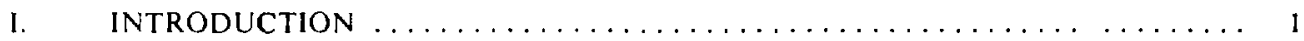

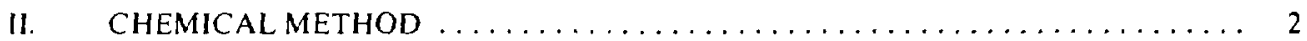

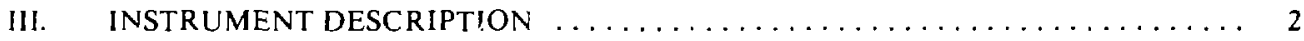

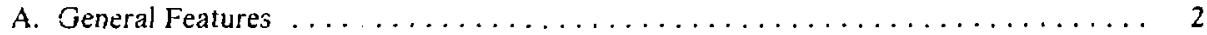

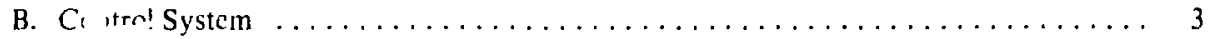

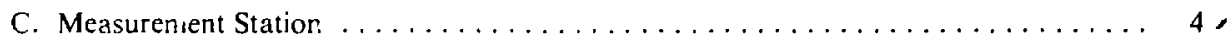

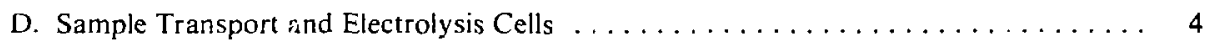

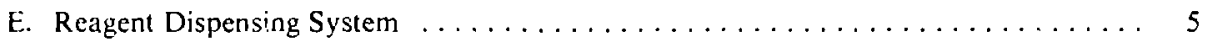

F. Cell. Stirrer. anit Electrode Cleaning System $\ldots \ldots \ldots \ldots \ldots \ldots \ldots \ldots$

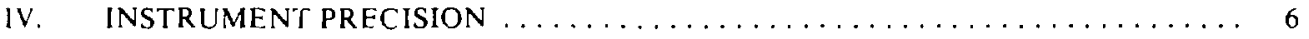

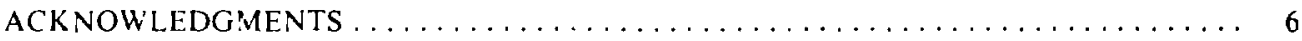

APPENDIX A. PREOPERATIONAL ADJUSTMENITS AND TESTS $\ldots \ldots \ldots \ldots \ldots \ldots \ldots 7$

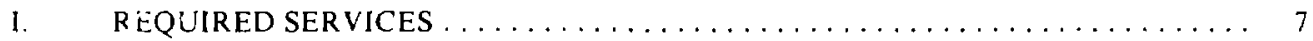

11. REAGENT DISPENSING AND CLEANING SYSTEMS $\ldots \ldots \ldots \ldots \ldots \ldots \ldots$

III. WORKING ELECTRODE ALIGNMENT $\ldots \ldots \ldots \ldots \ldots \ldots \ldots \ldots \ldots \ldots$

IV. OVERALL INSTRUMEN,T RELIABILITY $\ldots \ldots \ldots \ldots \ldots \ldots \ldots \ldots \ldots \ldots$

APPENDIX B. OPERATIONAL. PROCEDURE FOR PLUTONIUM DETERMINATION . . 8

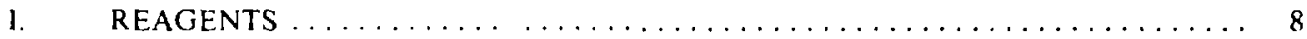

1I. ELECTRICAL TEST OF OVERALL ELECTRONIC SYSTEM $\ldots \ldots \ldots \ldots \ldots \ldots$

III. CHEMICAL CALIBRATION $\ldots \ldots \ldots \ldots \ldots \ldots \ldots \ldots \ldots \ldots \ldots \ldots$

IV. BRIDGE TURE MAINTENANCE $\ldots \ldots \ldots \ldots \ldots \ldots \ldots \ldots \ldots \ldots \ldots$

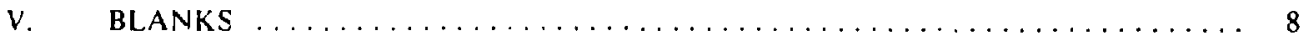

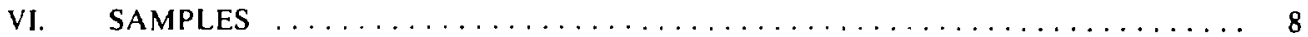

APPENDIX C. MECHANICAL COMPONENTS $\ldots \ldots \ldots \ldots \ldots \ldots \ldots \ldots \ldots \ldots \ldots$

APPENDIX D. ELECTRICAL CIRCUITRY $\ldots \ldots \ldots \ldots \ldots \ldots \ldots \ldots \ldots \ldots \ldots \ldots \ldots \ldots \ldots \ldots \ldots$ 
REFERENCES 


\section{LIST OF FIGURES}

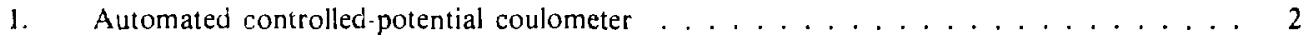

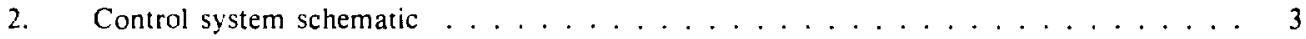

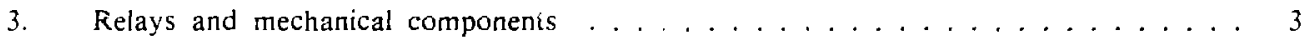

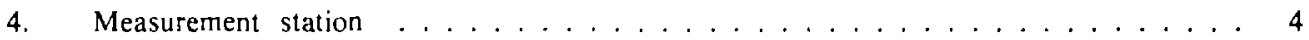

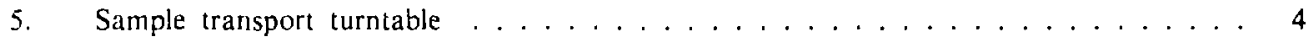

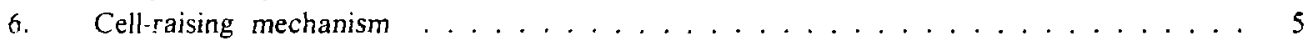

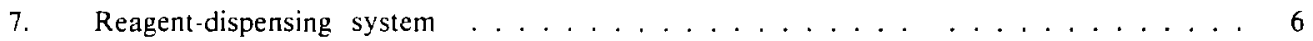

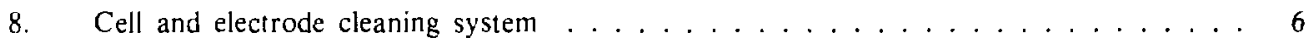

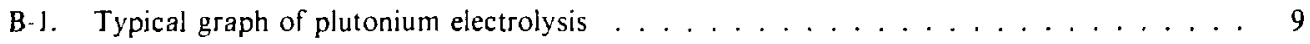

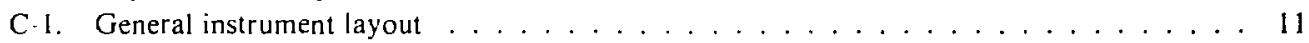

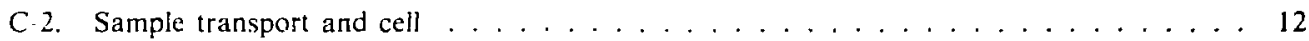

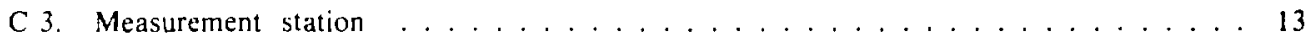

C.4. Reagent dispensers ....................... 14

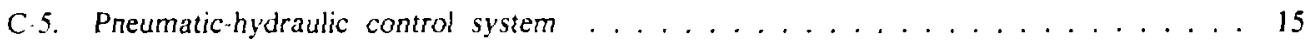

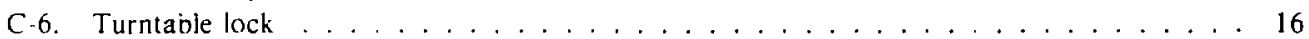

C. 7. Reagent dispenser components .................... 17

C.8. Miscellaneous supports ....................... 18

C.9. Measurement station supports ...................... 19

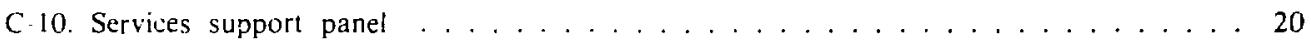

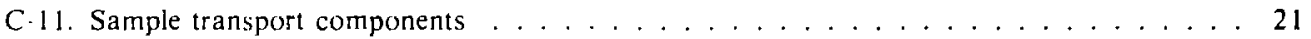

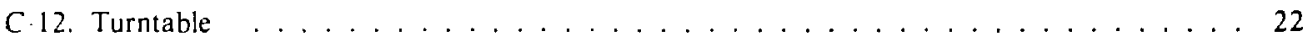

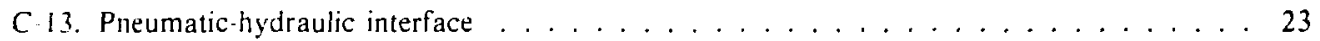

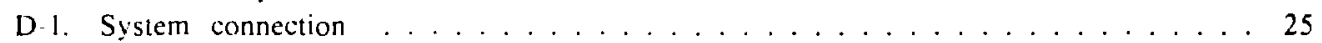

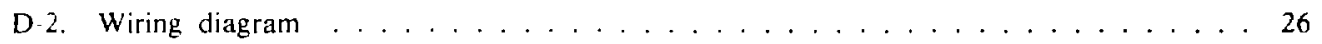

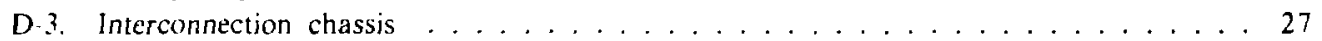

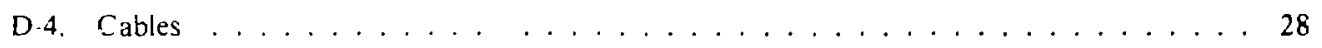

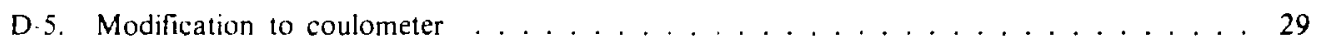

E-1. Sample program flow diagram .................. 31

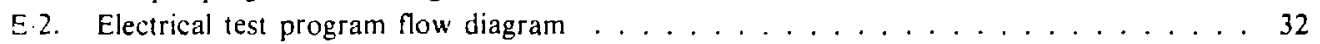

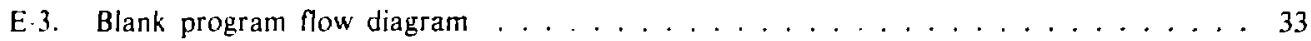

\section{LIST OF TABLES}

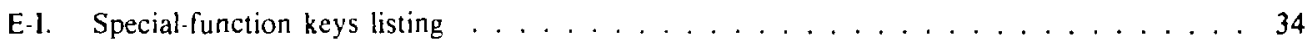

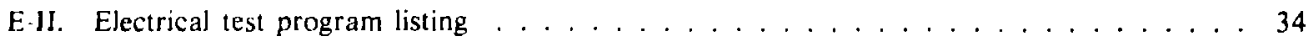

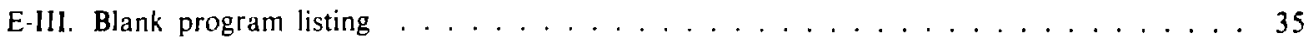

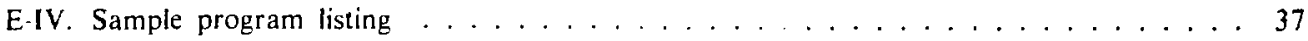




\title{
AUTOMATED CONTROLLED-POTENTIAL COULOMETER FOR PLUTONIUM DETERMINATION
}

\author{
by
}

\author{
R. M. Hollen and D. D. Jackson
}

\begin{abstract}
The automated controlled-potential coulometer for the determination of plutonium described in this report is the second in a series of automated instruments designed to determine plutonium and uranium contents in nuclear fue! cycle materials. The n:easurement precision of the instrument is $0.1 \%$ relative standard deviation at the 5-mg plutonium level.

A highly selective method of analysis was de"zloped, involving reduction of plutonium to $\mathrm{Pu}(\mathrm{III})$ in a $5.5 \mathrm{M}$ hydrochloric acid-0.015 $M$ sulfamic acid electrolyte; oxidation of diverse ions, but not $\mathrm{Pu}$ (III); addition of phosphate complexant to reduce the $\mathrm{Pu}(\mathrm{III})-\mathrm{Pu}(\mathrm{IV})$ potential; and oxidation of $\mathrm{Pu}(\mathrm{III})$ to $\mathrm{Pu}(\mathrm{IV})$ as the measurement step.

A turntable rotates as many as 24 electrolysis cells to a measurement station where all chemical and electrical operations take place. Reagents are added, solutions electrolyzed, daia printed and plotted, and the cell and electrodes cleaned. The instrument controller is a desk-top programmable calculator. A paper-tape printout gives date and time, a sample identification number, slectrolysis elapsed times, and numbers of coulombs for each electrolysis.

Construction details of the mechanical and electricai systems of the instrument and control-system software are described, along with instrument preoperational adjustments and tests and sample analysis operations.
\end{abstract}

\section{INTRODUCTION}

This automated controlled-potential analyzer, the second in a series of automated instruments designed to determine uranium and plutonium contents, was developed under sponsorship of the Office of Safeguards and Security, US Department of Energy. The first instrument was an automated spectrophotometer for the highly selective determination of low milligram amounts of uranium and plutonium with precisions of about $1 \%$ relative standard deviat:on ( $\left.\mathbf{R S}^{n}\right) .{ }^{\prime}$ This instrument was later modified ${ }^{2}$ to use an additional spectrophotometric method $^{3}$ to selectively determine microgram amounts of uranium. The automated controlled-potential analyzer described here determines low milligram amounts of flutonium with high selectivity and a $0.1 \%$ RSD.

The chemical method developed specifically for the in strument has been published ${ }^{4}$ and is discussed briefly here. Major mechanica! and electrical somponents of the instrument are discussed, and test data that show its precision capability are given. Appendix A provides preoperational adjustments and tests. and an operational 
procedure for determining plutonium is given in Appendix B. Other Appendixes provide details of mechanical components including construction drawings (Appendix C), electrical components including circuit diagrams (Appendix D), and control-system software (Appendix E).

\section{CHEMICAL METHOD}

The major criteria for the chemical method were high selectivity, precision of $0.1 \%$ RSD at the $5 \cdot \mathrm{mg}$ plutonium level. determination of total plutonium regarcless of initial oxidation state. and long-term electrode stability. Because no available method met all requirements, we developed a highly selective, controlled-potential coulometric method for determining total plutonium. ${ }^{4}$ In a 5.5M HC1-0.015M sulfamic acid electrolyte, plutonium is reduced at $0.25 \mathrm{~V}$ to $\mathrm{Pu}(\mathrm{III})$. (All potentials are relative to the saturated-calomel electrode.) Many diverse ions, including iron, are oxidized at a potential of $0.57 \mathrm{~V}$. Phosphate (as $\mathrm{NaH}_{2} \mathrm{PO}_{4}$ ) is added to make the electrolyte $1 M$ in phosphate, which lowers the $\mathrm{Pu}(\mathrm{III})$ $\mathrm{Pu}(\mathrm{IV})$ potential, and $\mathrm{Pu}(\mathrm{III})$ is oxidized to $\mathrm{Pu}(\mathrm{IV})$ at $0.68 \mathrm{~V}$ as the measurement step. All electrolyses are performed to a $50-\mu \mathrm{A}$ current endpoint. The tolerances of 53 metal ions and 25 nonmetal anions are given in Ref. 4. Metal cations normally present in nuclear fuel cycle materials do not interfere at an equal mole ratio relative to $0.02 \mathrm{mmol}(5 \mathrm{mg})$ of plutonium. Many anions are without effect, and most interfering ones are removed by perchloric acid fuming. Under normal operating conditions, the platinum-gauze working electrode remains stable for months.

Precision for the method is typically $<0.1 \%$ RSD for a single determination at the $5-\mathrm{mg}$ plutonium level. This represents the total random measurement error. including components from weighing and chemical operations.

\section{INSTRUMENT DESCRIPTION}

\section{A. General Features}

The automated controlled-potential coulometer. shown in Fig. 1, features a curntable that rotates up to 24 electrolysis cells to a measurement station. All operations are automated, including sample transport, reagent

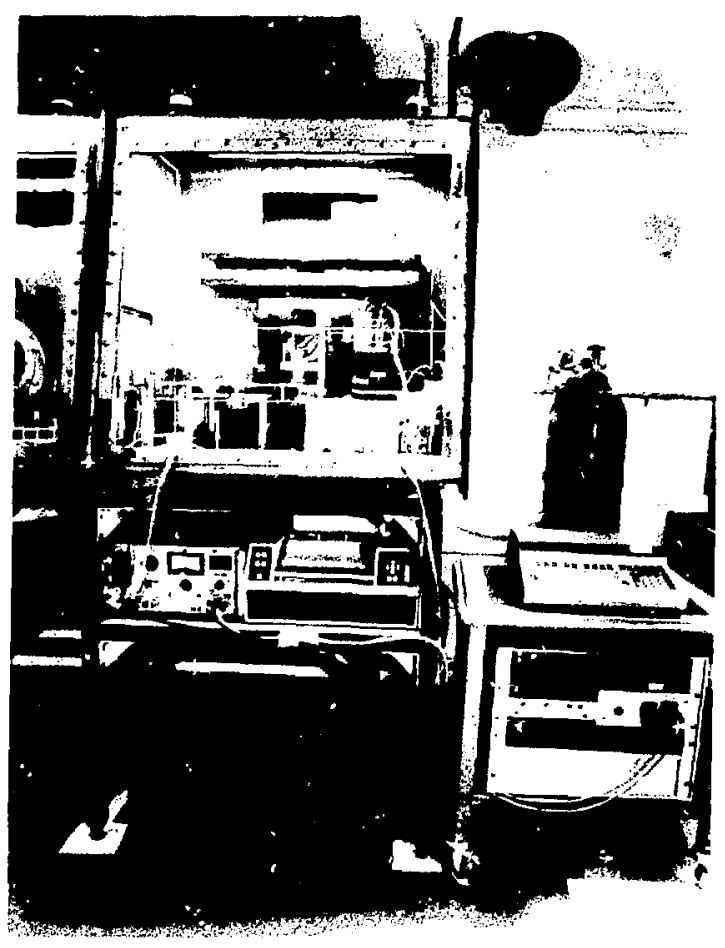

Fig. 1.

Atitomated controlled potentikl coulometer.

deliveries, the reduction and two oxidation electrolyses. data computation with output on paper tape and a display of the electrolyses (current vs time), and cleaning of cells, stirrer. and electrodes. The analyst delivers weight or volume portions of samples, containing nominally 5 $\mathrm{mg}$ of plutonium in a volume up to $2 \mathrm{~mL}$. into cells. places the cells in the turntable, and initiates the automated operation. The analysis rate is about one per $30 \mathrm{~min}$. A programmable calculator controls al! mechanical and electrical operations and processizs data.

The mechanical system is designed to fit in a single open front box $0.91 \mathrm{~m}$ wide, $0.79 \mathrm{~m}$ deep at the base. ancj $0.84 \mathrm{~m}$ high. A 0.30 -m-high front openung gives ready accessibilitv to the turntable, measurement station, and reagent containers. Instrument layout provides accessibility to the measurement station components and ease of servicing. The mechanical components of the instrument are designed for long-term reliability. Most parts are fabrivated of aluminum, Teflon, Kel-F, or nylon to minimize corrosion. Waste solution is collected in a bottle outside the box. Interlocks are incorporated to 
minimize the possibility of instrument damage or a faulty analysis. Indication of possible damage to the instrument terminates operation. If only the analysis is affected, automated operation continues, but the analysis is terminated.

Most electronic components are available commercially for ready replacement and simplified maintenance. These components, located outside the box, connect to the mechanical system by four cables.

\section{B. Control System}

The control system is shown schematically in Fig. 2. A Hewlett-Packard 9825A Programmable Calculator with 98210.A String-Advanced Programming and 98216A Plotter-General I/O - Extended I/O ROMs and 98034A HPIB and 98033A BCD Interface Cards controls all mechanical and electrical operations, processes electrolysis data, prints results on paper tape, and plots graphs of the electrolyses. Programs are written in HPL, a high-level language. The sequence and timing of the operations are controlled accurately by the calculator. Real-time decisions affecting the analysis are made and acted upon. Separate programs (Appendix E) are used for processing blanks (for background correction), analyzing samples, and verifying correct electrical operation. Special function keys on the calculator allow manual control of all operations to facilitate adjustments.

Interfaced and under calculator control are a digitalto-analog converter (DAC), a digital multimeter (DMM), a scanner, a real-time clock, and a digital plotter. The DAC allows selection of electrode potentials by supplying a highly stable voltage to the externai signal input of

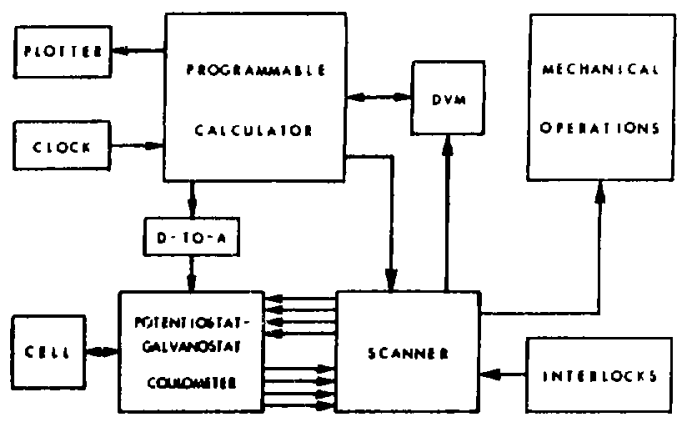

Fig. 2.

Control system schematic. the potentiostat. The DMM measures electrolysis current and applied potential and serves as an analog-to-digital converter to read in data to the calculator. The DMM also monitors the interlocks. Instrument operation stops if (1) the inert-gas supply ceases, (2) a cell does not lower correctly into position in the turntable, (3) the turntable locking mechanism fails, (4) the turntable does not rotate to its correst angular position, or (5) the cell does not raise correctly into position at the measurement station. The potentiostat output is monitored. If an electrical malfunction is indicated, the potentiostat output is switched off and mechanical operation is stopped. After the last sample is analyzed and the cell. stirrer. and electrodes are cleaned, rinse solution is added to immerse the working electrode, and operation is stcpped.

The real-time clock monitors electrolysis times. If elapsed time exceeds preset values considered to affect results adversely. that analysis is - minated and automated operation continues. The prujuced graph of log currcnt vs time provides diagnostic information. The scanner selects the input signal to the DMM and controls the mechanical operations through contact closures. Photo-isolated relays, shown on the left in Fig. 3. isolate the calculator and potentiostat from large transients generated by solenoids and motors. A Princeton Applied Research Corporation 173 Potentiostat-Galvanostat and 179D Digital Coulometer do the electrolysis. The poten tiostat is modified for calculator control of the selector switch, and the coulometer is interfaced for calculator control, as detailed in Appendix D.

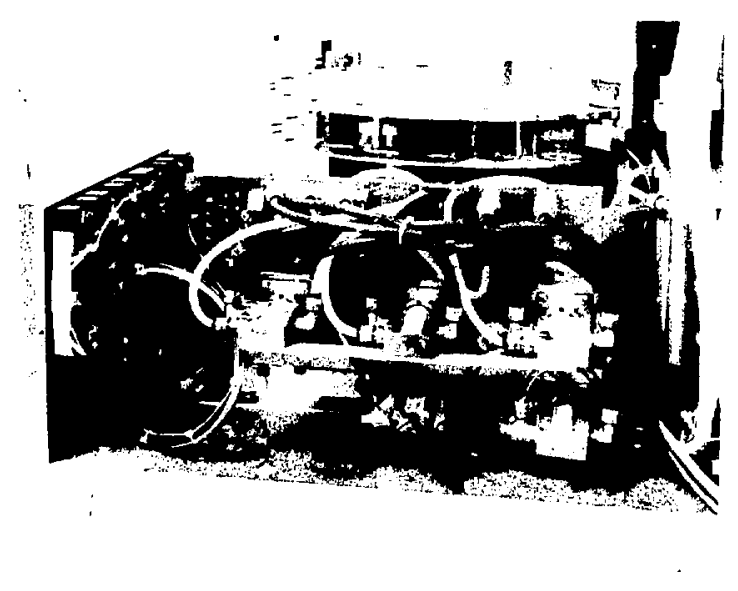

Fig. 3.

Relays and mechanical components. 


\section{Measurement Station}

At this station, a rigid Teflon support holds the electrodes, reagent and inert-gas delivery tubes, stirring unit, and rinsing unit (Fig. 4). The fixed support prevents flexing of electrical leads and tubing, which could cause failure. The positions of the cell components provide reliable electrolyses and servicing access.

The working electrode is a three-layer, folded, 45 . mesh platinum gauze with two 14-gauge platinum wires fused to it. The large surface area provides fast electrolyses. The two wir zs pass through close-fitting holes in the Teflon support to attain alignment rigidity, required for correct cell positioning and effective cleaning. The alignment procedure is detailed in Appendix A.

The counter electrade is 18-gauge platinum wire with one end folded for increased surface area. The reference electrode is a Peckman Model 392-70 saturated-calomel electrode. Commercial bridge tubes with porous $v y c o r$ frits, detailed in Appendix C, are used for both the counter and reference electrodes. The Vycor frits, which provide high electrical conductivity at very low flow

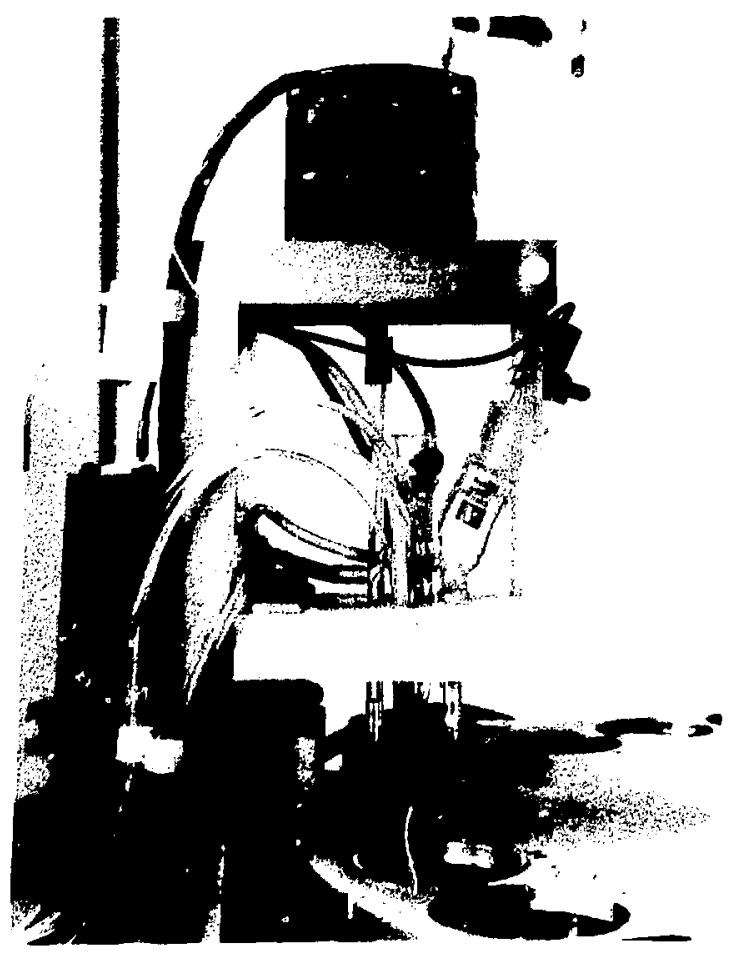

Fig. 4.

Measurement station. rates of electrolyte, are attached with heat-shrinkable Teflon tubing. The tip of the reference bridge tube is located adjacent to the working electrode for best control. The counter electrode is in the geometric center of the working electrode to attain a uniform potential gradient. A drawing of the cell is given in Appendix $\mathbf{C}$.

Effective stirring is provided by a glass paddle driven hy an 1800-rpm synchronous motor mounted rigidly above the Teflon support. The paddle, about $1.0 \mathrm{~cm}$ wide, $0.6 \mathrm{~cm}$ high, and $0.3 \mathrm{~cm}$ thick, is made by flattening the heated end of a $0.5-\mathrm{cm}$-diam glass rod. The Teflon support provides a low-friction bearing surface preventing wobble. The stirring rod is connected to the motor spindle by a flexible coupling of rubber tubing.

A 2.7-atm inert gas supply of argon or nitrogen with $<400 \mathrm{ppm} 0_{2}$ provides the cell purge and drives all pneumatic and hydraulic operations. The purge gas pressure is reduced to $0.2 \mathrm{~atm}$ with a miniature pressure regulator inside the mechanical system. A needle valve regulates the purge flow to $750 \mathrm{~cm}^{3} / \mathrm{min}$, and an in-line flow switch monitors the purge flow. The inlet and outlet tubes are $0.5 \mathrm{~cm}$-diam glass tubing bent $90^{\circ}$ at the point of emergence from the upper side of the Teflon support.

\section{Sample Transport and Electrolysis Cells}

The curntable (Fig. 5) is rotated by a Geneva-drive, intermittent-motion assembly that provides slow acceleration and accurate positioning. A cylindrical rod driven by a pneumatic cylinder that engages indentations

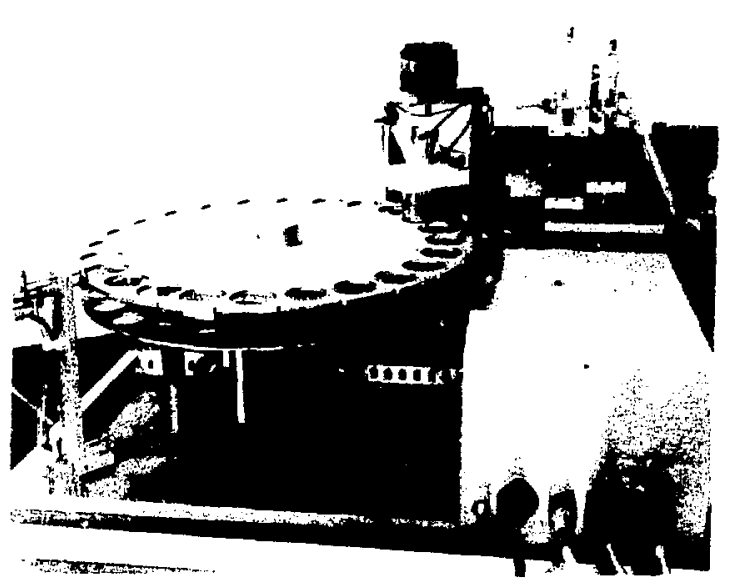

Fig. 5.

Sample transport turntable. 
miled in the turntable rim at each of the 24 positions provides a table locking mechanism and ensures position accuracy. As part of an interlock system, a switch on the locking mechanism monitors its status. The analyst reads in the position number (1-24 on the turntable) of the first cell in a series, and the calculator prints and plots the position number associated with each analysis result.

The turntable and pneumatic-hydraulic cell-raising mechanism (Fig. 6) provide accurate positioning of a cell

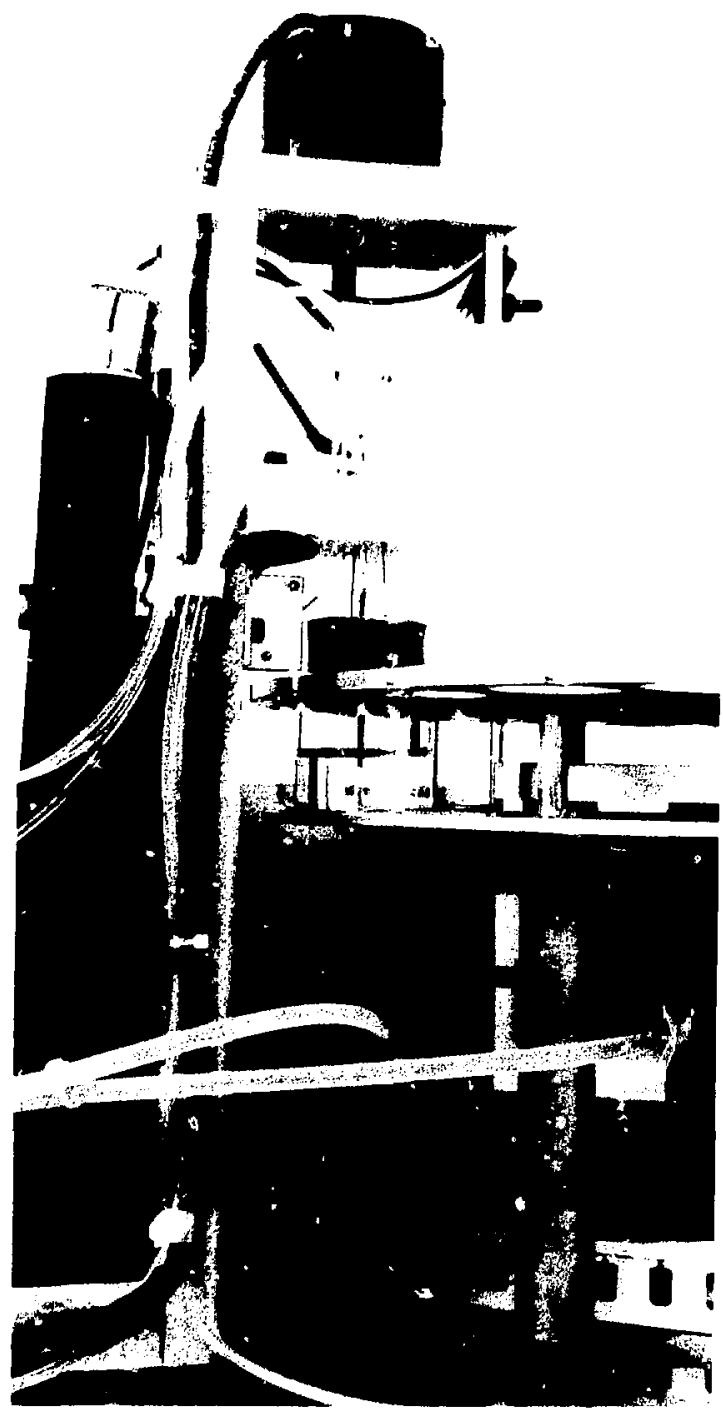

Fig. 6.

Cell-raising mechanism. relative to the close-fitting working electrode, as well as a tight seal with the Teflon support. The close-fitting holes in the upper portion of the turntable guide cells into position. A Teflon sheet on the lifting disk provides a lowfriction surface that prevents wedging of cells during the raising operation. To lessen force on the cells, the hydraulic cylinder of the cell-raising mechanism is driven with a reduced pressure of $1.4 \mathrm{~atm}$ by a miniature pressure regulator. The slow speed required for correct operation is set with a needle valve. A low-torque, whisker-actuated switch at the measurement station in forms the calculator that a cell is correctly in position. A small scanner assembly, consisting of a light and phototransistor mounted in the same housing. detects the last cell, and instrument operation stops.

The electrolysis cells are simple to fabricate from glass tubing of $4.8-\mathrm{cm}$ diarı and $0.2 \mathrm{-cm}$ wall thickness. The total cell height is $4.5 \mathrm{~cm}$ with $\pm 0.05-\mathrm{cm}$ tolerance to prevent damage to the working electrode and to attain effective aspiration of solution. The flat cell bottom avoids interference with the stirrer paddle and attains effective aspiration. The cell top is ground flat and fire-polished lightly to produce a gas-tight seal with the Teflon support.

\section{E. Reagent Dispensing System}

This system (Fig. 7) is patterned on those developed for the automated spectrophotometer. These systems have provided years of reliable service and maintained high precision while handling corrosive reagents. In the automated coulometer system, only glass and Teflon contact the corrosive reagents. The system combinis pneumatic and hydraulic transducers that provide a smooth, reproducible motion to gas-tight syringes. Delivery volume is set by adjustable stops on the hydraulic cylinder. Precision, determined by weighing dispensed reagents, is better than $0.01 \%$ RSD for $23-\mathrm{mL}$ volumes of the $5.5 \mathrm{M} \mathrm{HCl}-0.015 \mathrm{M}$ sulfamic acid electrolyte and $5-\mathrm{mL}$ volumes of the $5 M$ phosphate solution. Construction is detailed in Appendix B and preoperationil adjustment is given in Appendix A.

\section{F. Cell, Stirrer, and Electrode Cleaning System}

A!l cell components must be cleaned thoroughly between samples. The large surface-area working electrode is difficult to clean without large volumes of rinse. Of 


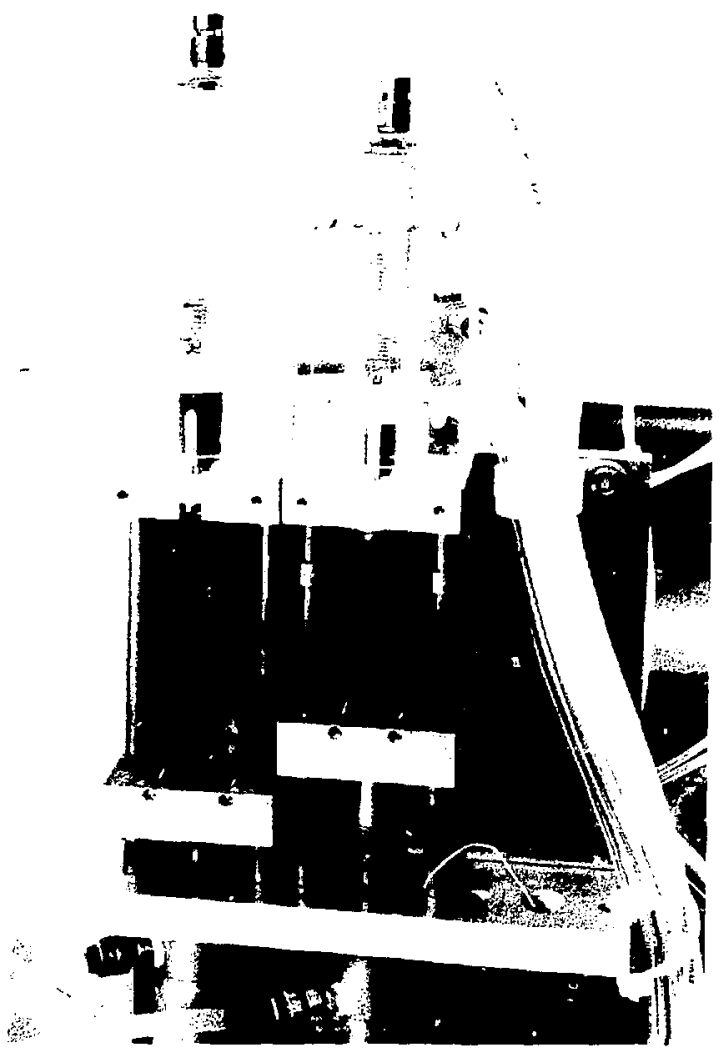

Fig. 7.

Reagent-dispensing system.

many approaches tested, the most effective is to place the tip of an aspiration tube at an exact position at the junction of the working electrode and cell bottom. Exact positioning of the Teflon aspirator tube is attained by moving it pneumatically through a Teflon guide tube (Fig. 8). Aspiration is provided by a 1.8-cfm-diaphragm air pump operating at $-0.6 \mathrm{~atm}$. The percentage of solution removed using an initial aspiration and two rinseaspiration combinations is $>99.98$.

A Teflon nutating-disk pump delivers the rinse solution. A concurrently activated two-way valve in the output line preveni: solution flowing back to the pump. The pump voltage controls the delivery rate, and the elapsed tir re of operation controls the volume.

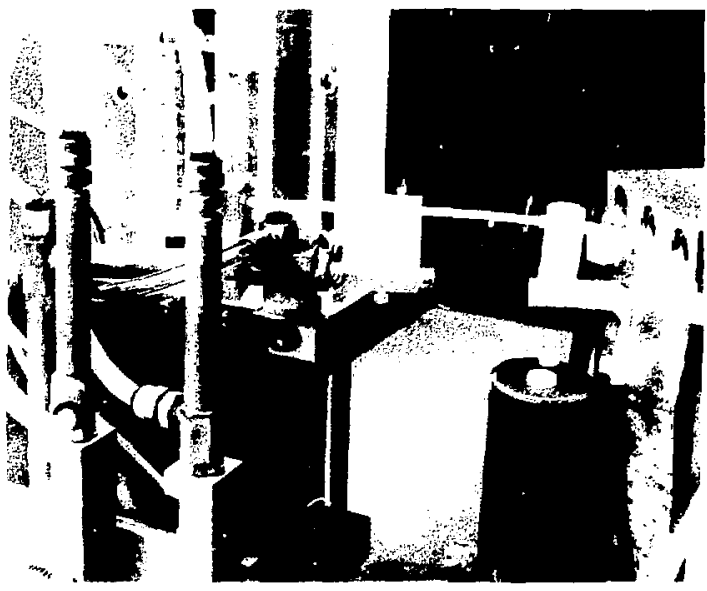

Fig. 8.

Celf and electrode cleaning system.

The $\sim 80$ - $\mathrm{mL}$ waste volume per analyzed sample flows through a Teflon tube encased in a larger Teflon tube to a bottle mounted outside the box. The bottles are easily changed

The cleaning sequence is (1) insert aspirator tube and remove solution, (2) add $\sim 4-\mathrm{mL}$ of rinse solution whils aspirating. (3) withdraw aspirator tube, (4) add rinse solution to the height of the maximum sainple volume, (5) stir, (6) aspirate, (7) withdraw aspirator tube, (8) add a slightly greater volume of rinse solution, (9) stir, (10) aspirate, and (II) withdraw aspirator tube. A detailed description is given as subroutine "rinse" in Fig. E-1.

\section{INSTRUMENT PRECISION}

Measurement precision was established by processing weight aliquots, containing $\sim 5 \mathrm{mg}$ of plutonium each, of a reference material solution. Eight aliquots per day were processed over a 2 -week period. The average within-day RSD for a single determination was $0.082 \%$. Long-term precision, computed using all data, was $0.096 \%$ RSD.

\section{ACKNOWLEDGMENTS}

Design of the automated controlled-potential coulometer entailed the efforts of many Los Alamos National Laboratory personnel. In particular, credit is 
due A. Criscuolo for designing the potentios'at modification, P. Osvath for mechanical drawings, and R. Plehn for electrical irawings. J. E. Rein provided general guidance and preediting assistance.

\section{APPENDIX A}

\section{PREOPERATIONAL INSTRUMENT ADJUSTMENTS AND TESTS}

Preoperational adjustments and tests are described for the reagent dispensing and cleaning systems, alignment of the working electrode, and overall operational reliability. The adjustments are made most conveniently by manual control using the calculator special-function keys and the program given in Table E-I

\section{REQUIRED SER YiCES}

Electrical service requirements are $120 \mathrm{~V}, 15 \mathrm{~A}$, and $60 \mathrm{~Hz}$. A 2.7 atm inert-gas supply of nitrogen or argon, containing $<400 \mathrm{ppm}$ oxygen, is required.

\section{REAGENT DISPENSING AND CLEANING SYSTEMS}

The dispensed volumes of the electrolyte and phosphate solutions are adjusted by mechanical stop positions on the hydraulic cylinder mechanisms. Just enough electrolyte is added to cover the platinum working electrode. The phosphate solution is dispensed to provide a $I M$ phosphate concentration in the cell solution, calculated disregarding sample volume. Volumes of rinse solution are controlled by programming the elapsed time of pump operation.

To avoid splashing, the delivery tips dispense all solutiuns onto the bridge tube of the counter electrode. The tips are cut at $45^{\circ}$ and bent slightly toward the bridge tube.

Premature delivery of the phosphate solution is prevented by separating the three dispenser tips by $\sim 1$ $\mathrm{mm}$. The electrolyte tip is lowest, the phosphate tip next, and the rinse tip on top, so that any adhering electrolyte and phosphate solutions are removed during the rinse operation.

Delivery rates of the electrolyte and phosphate solution dispensers are adjuited by needle valves in the hydraulic syst'm to provide smooth motions of the syringe plungers and stculy rate deliveries without splashing. The delivery rate of the rinse pump is adjusted to $\sim 2 \mathrm{~mL} / \mathrm{s}$.

\section{WORKING ELECTRODE ALIGNMENT}

Careful positioning of the working electrode is required for unhinciered operation of the cell-raising system and for efficient aspiration. The working electrode bottom must be flat and parallel to the turntable surface. The electrode is positioned centrally in the turntable holes at a height so its bottom is $4.3 \mathrm{~cm}$ below the Teflon support. System alignment is attained using a plastic jig counterbored slightly larger than the outer diameter of the working electrode. The jig. positioned on the turntable at the measurement station, is raised manually. and the working electrode wires are adjusted so the electrode is centered in the jig counterbore. The tip of the aspirator tube is positioned at the junction of the working electrode and tine cell bottom, so that solution is removed effectively from the working electrode and cell by capillary action.

\section{OVERALL INSTRUMENT RELIABILITY}

Overall instrument reliability is evaluated by processing weight aliquots containing $\sim 5 \mathrm{mg}$ of plutonium each. taken from a homogeneous solution. The precision dara presented in Sec. IV can serve as the basis $n$ ? com. parison. Causes of poor reproducibility include splashing by the stirrer, faulty solution dispensings, incomplete aspiration, electrode difficulties, and electronic malfunctions. The overall electronic system is tested according to the procedure given in Appendix B. 


\section{APPENDIX B}

\section{OPERATIONAL PROCEDURE FOR PLUTONIUM DETERMINATION}

\section{REAGENTS}

A. Electrolyte Solution, 5.5M HCi-0.015M Sulfamic Acid

Prepare $5.5 \mathrm{M} \mathrm{HCl}$ by passing hydrogen chloride into distilled-deionized water. then diluting with the same water as necessary, based on titration with standardized sodium hydroxide. Prepare the electrolyte by dissolving $1.46 \mathrm{~g}$ of $\mathrm{AR}$ grade sulfamic acid in the $5.5 \mathrm{M} \mathrm{HCl}$ to a final volume of 1 liter. This solution is stable for at least 2 months.

\section{B. Phosphate Solution, $5 \mathrm{M} \mathrm{NaH} \mathrm{PO}_{4}$}

Dissolve $690.0 \mathrm{~g}$ of $\mathrm{NaH}_{2} \mathrm{PO}_{4} \cdot \mathrm{H}_{2} \mathrm{O}$ in distilleddeionized water to a final volume of 1 liter. Of several brands evaluated, Mallinckiodt AR-grade has proven reliable.

\section{Rinse Solution, $6 M \mathrm{HCl}$}

Mix one volume of concentrated AR-grade $\mathrm{HCl}$ with one volume of distilled-deionized water.

\section{ELECTRICAL TEST OF OVERALL ELEC. TRONIC SYSTEM}

As a minimum, this test is made after a 15-min warmup at the beginning of a day's operation and again at the end. The data obtained are used to eliminate a small day to-day variance. typically less than $0.04 \%$. caused by slight instability of electronic components. ${ }^{4} \mathrm{~A}$ high-wattage, 100-ohm resistor is substituted for the cell, and a $1 . V$ potential from the potentiostat is applied for $10 \mathrm{~min}$. The calculator controls the coulometer and the real-time clock, which accurately measures the time interval. (The program flow diagram and program listing for this test are given in Fig. E-2 and Table E-Il.) The chemical calibration factor is adjusted by the ratio of the coulombs measured by the coulometer relative to the coulombs calculated from the time-current measuremeit.

\section{CHEMICAL CAIIBRATION}

As the reference material, NBS SRM 949 plutonium metal is used. For highest reliability, weight portions of a solution prepared with this reference material are processed concurrently with samples, and the sample results are computed relative to the reference material results. A less accurate operational mode is to use a calibration factor established at a previous time relative to NBS SRM 949 and verified within established control limits by the concurrent processing of one or two reference material portions.

\section{BRIDGE TUBE MAINTENANCE}

The two bridge tubes are rinsed and refilled with electrolyte solution before starting a day's operation.

\section{BLANKS}

As a minimum, a blank is processed through the complete electrolysis cycle of reduction. first oxidation, and measurement oxidation at the beginning and end of a day's operation. The accumulated times and coulombs are printed at 1 -min intervals for both oxidations. The program flow diagram and program listing are given in Fig. E-3 and Table E-III.

\section{SAMPLES}

Sámples containing $\sim 5 \mathrm{mg}$ of plutonium in a volume of $2 \mathrm{~mL}$ or less are delivered into cells, preferably by weight. The cells are placed on the turntable and the sample designations and turntable posicions are logged. The turntable position of the first sample (or blank or reference material) is read in to the calculator. Automated operation is initiated.

The tape printout consists of (1) real time. (2) turntable position. (3) elapsed times for the reduction and two oxidations. and (4) numbers of coulombs for the 
reduction and two oxidations. The number of coulombs measured for the blank at elapsed times equal to electrolysis times for the samples are subtracted from the number of coulombs for the sample. The graphic output (Fig. B-1) provides diagnostic information. The program flow diagram and program listing are given in Fig. E-1 and Table E-IV.

\section{SAMPLE NUMBER IC}

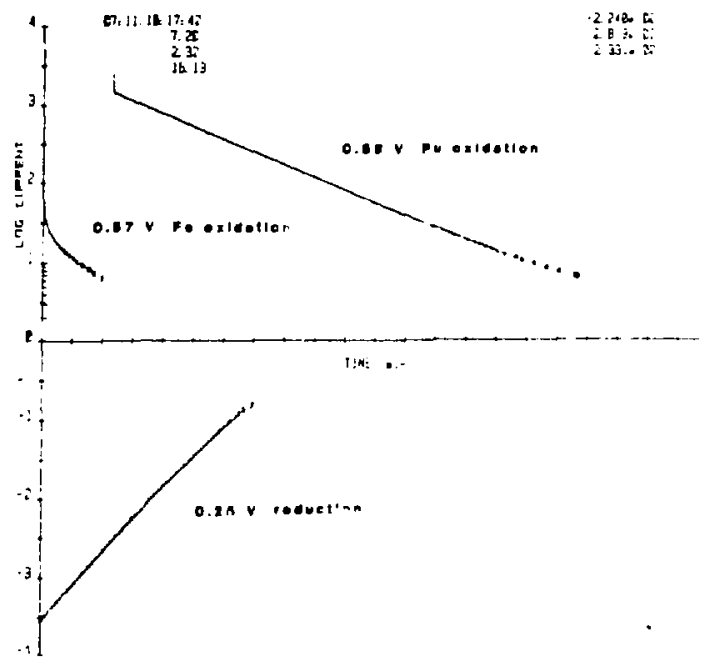

Fig. 81.

Typical graph of plutonium electrolysis. 


\section{APPENDIX C}

\section{MECHANICAL COMPONENTS}

Appendix $C$ consist of reduced copies of mechanical components including construction drawings for the atumated controlled potential coulometer. CAPE package number 2669 , which consists of working draw ings, may $1 \%$ purchased from the Technical Information Center. Oak Ridge. TN 37830. 


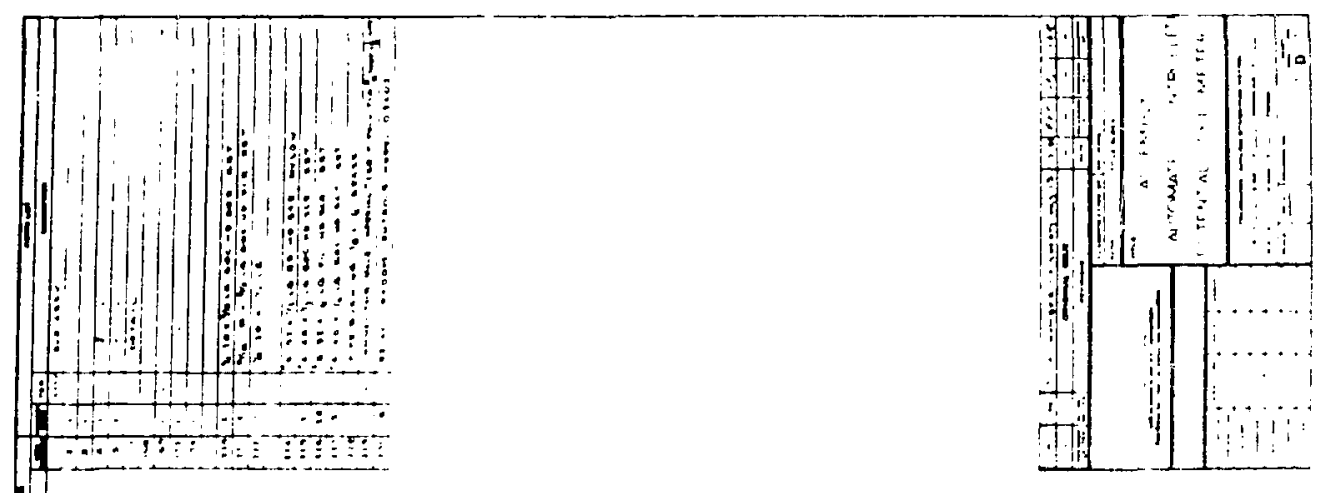

现

(a) 


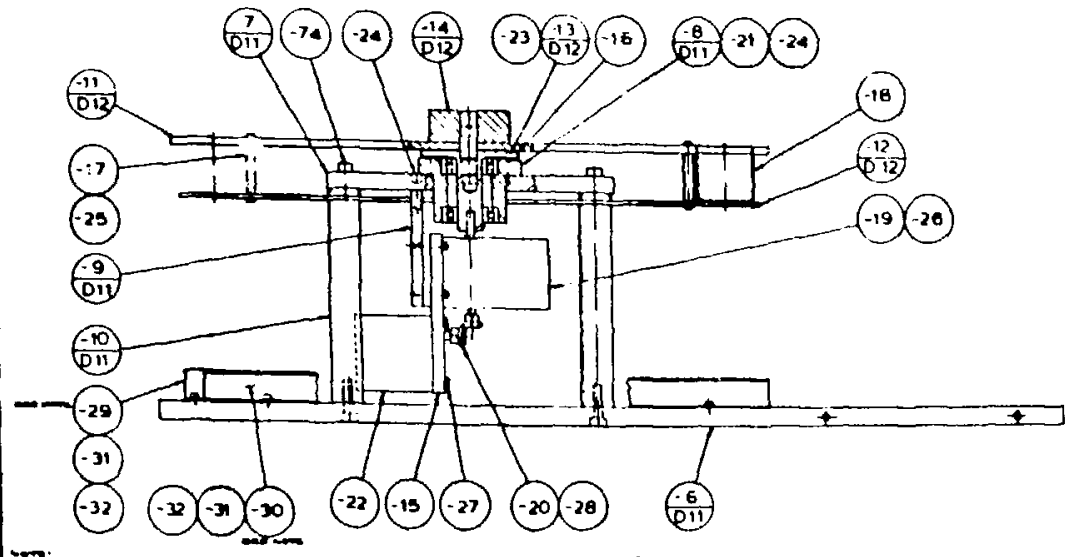

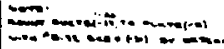

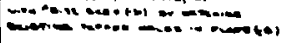

(a)

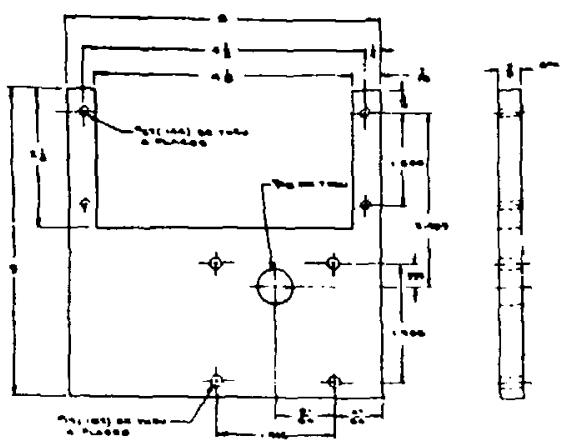

(19)

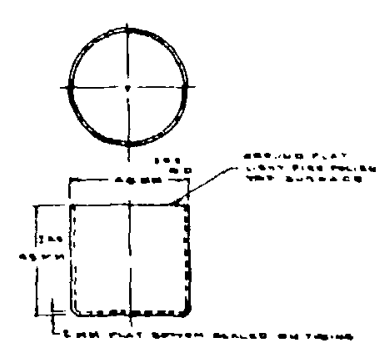

(-18)

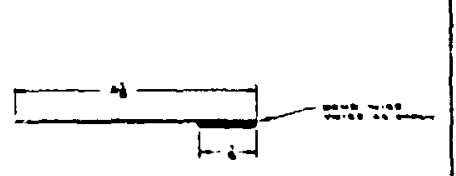

(28)

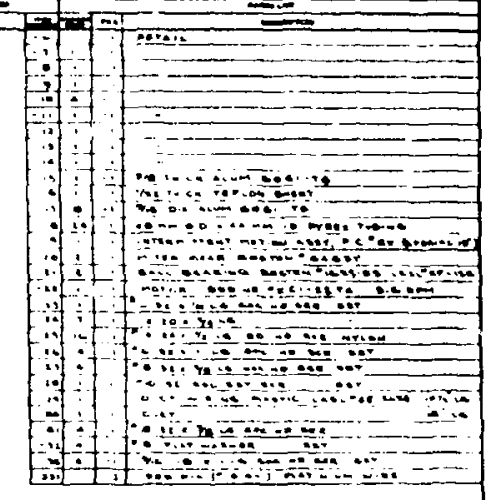

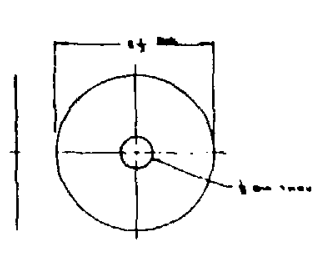

(-16)

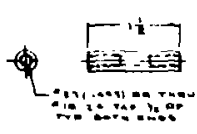

(17)

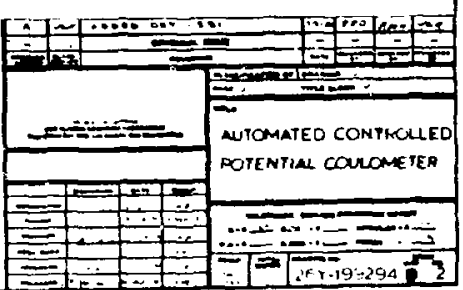

Fig. C. 2 .

Sample transport and cell. 


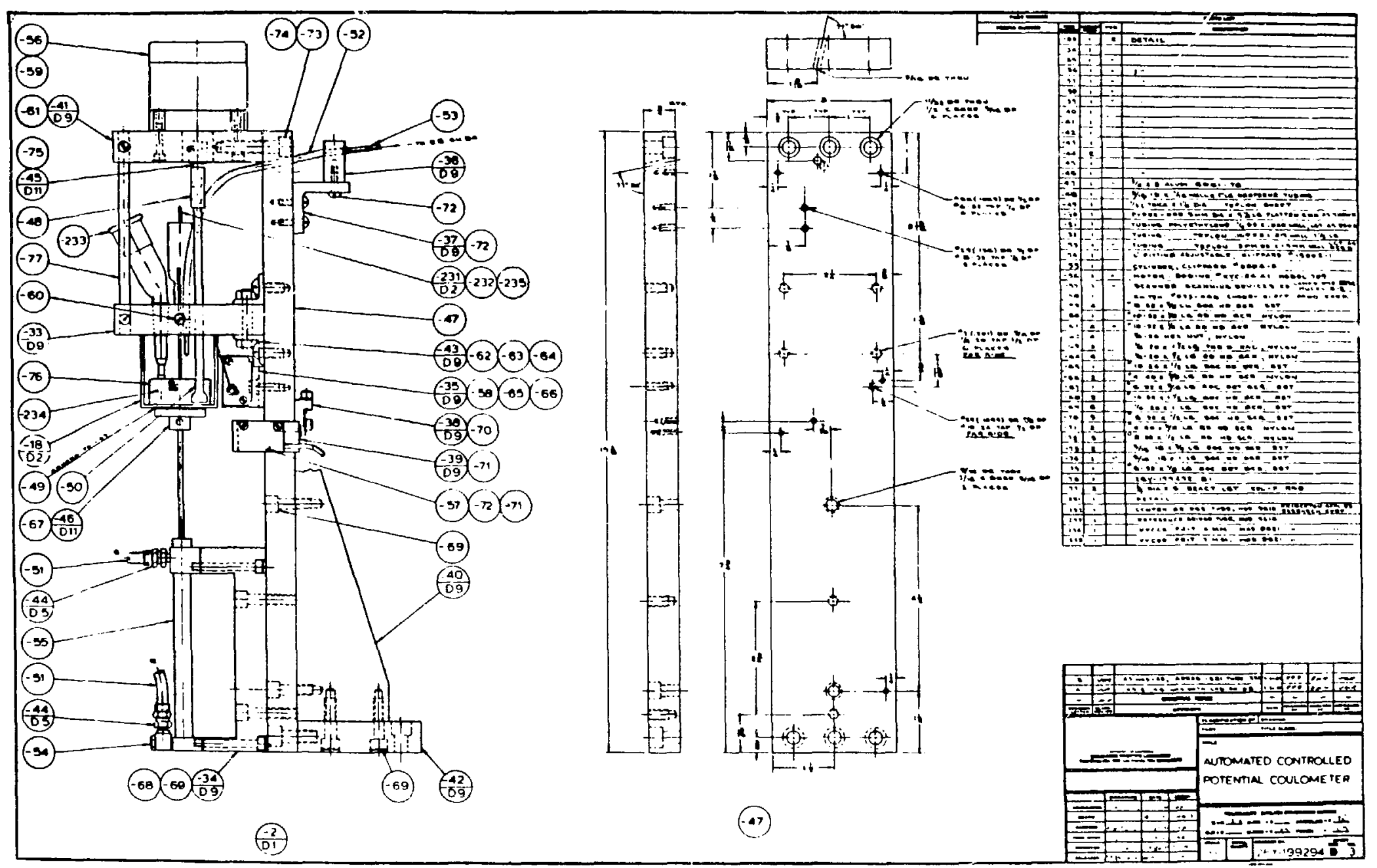

Fig. C. 3. 


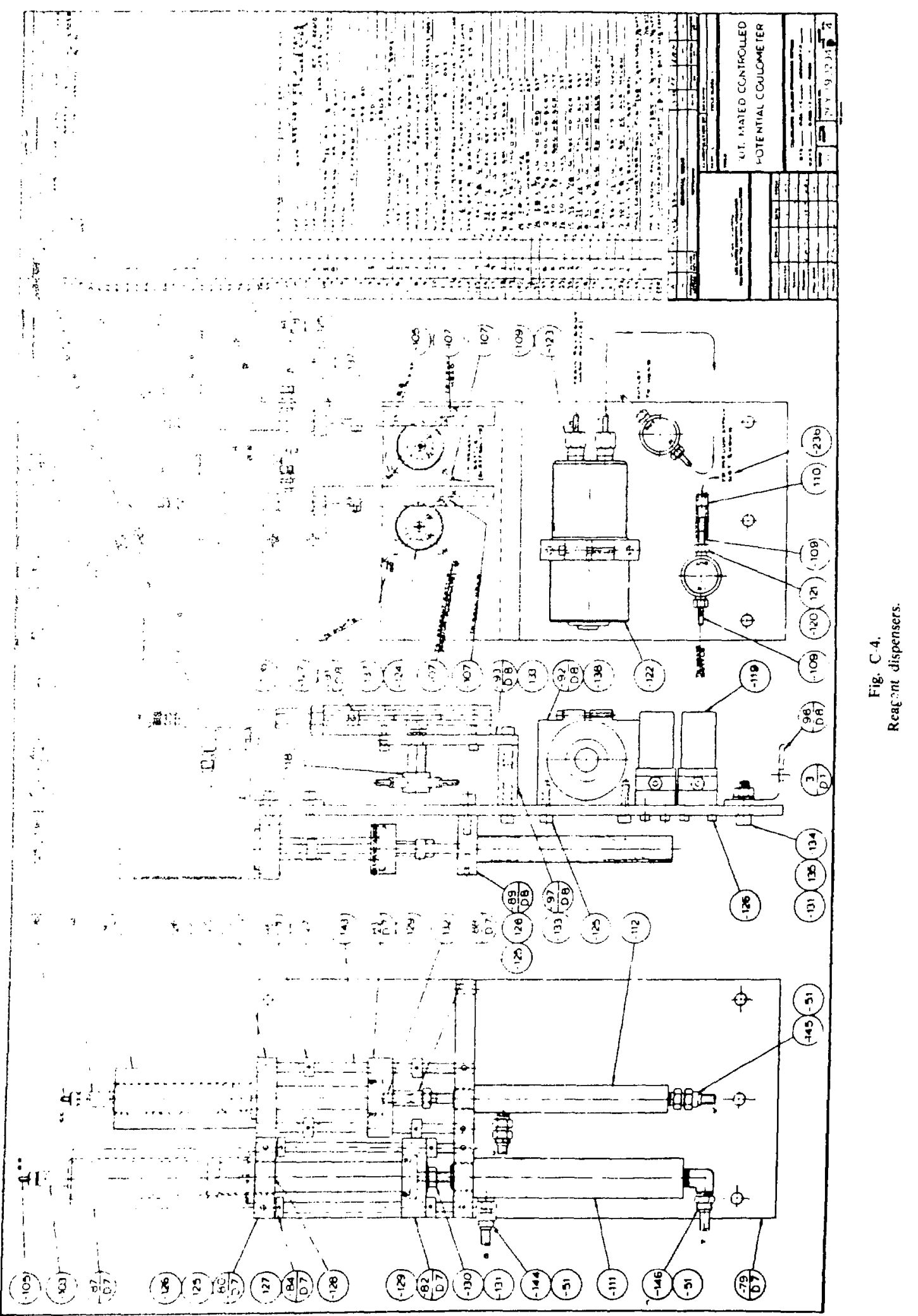




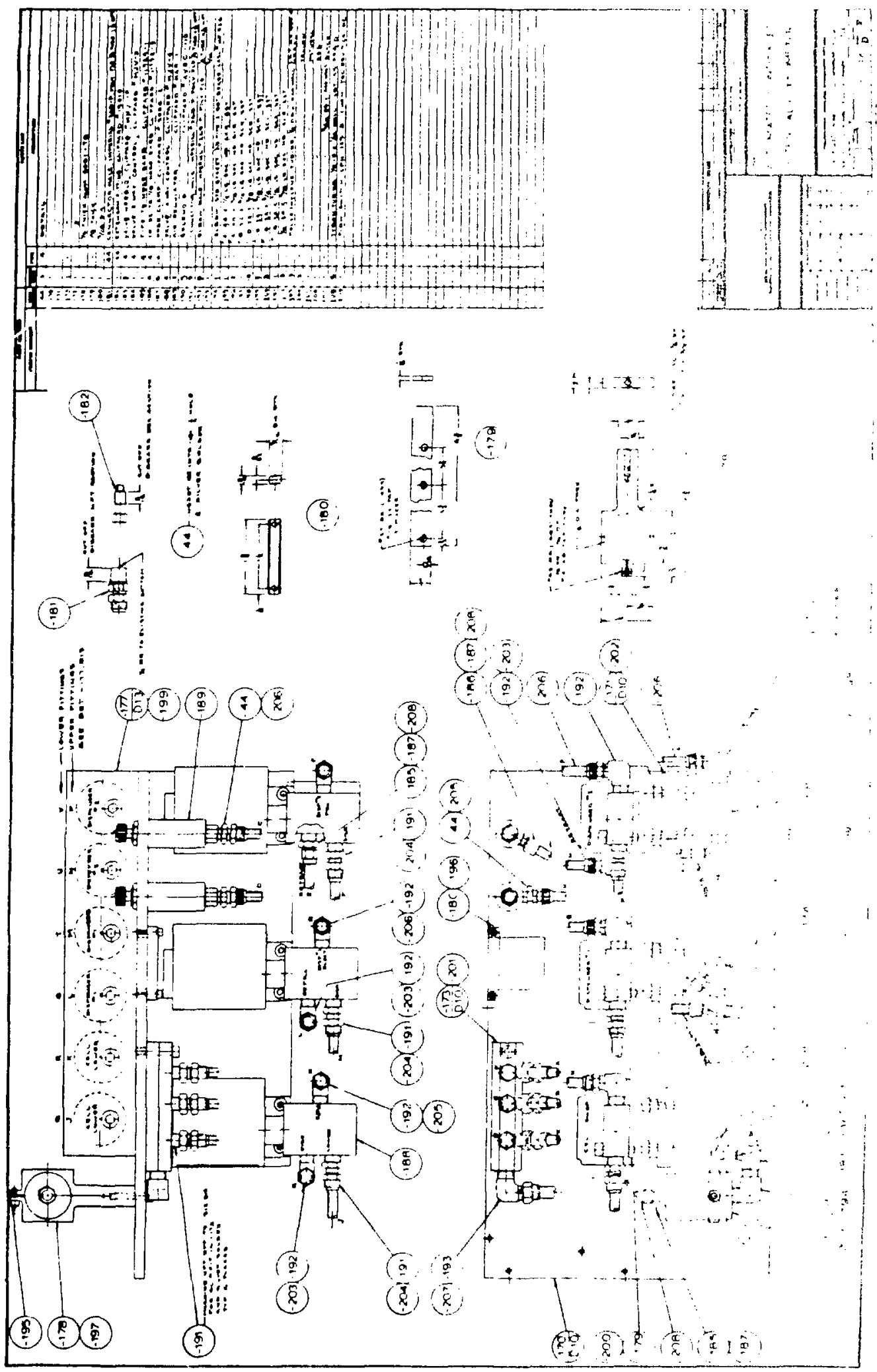




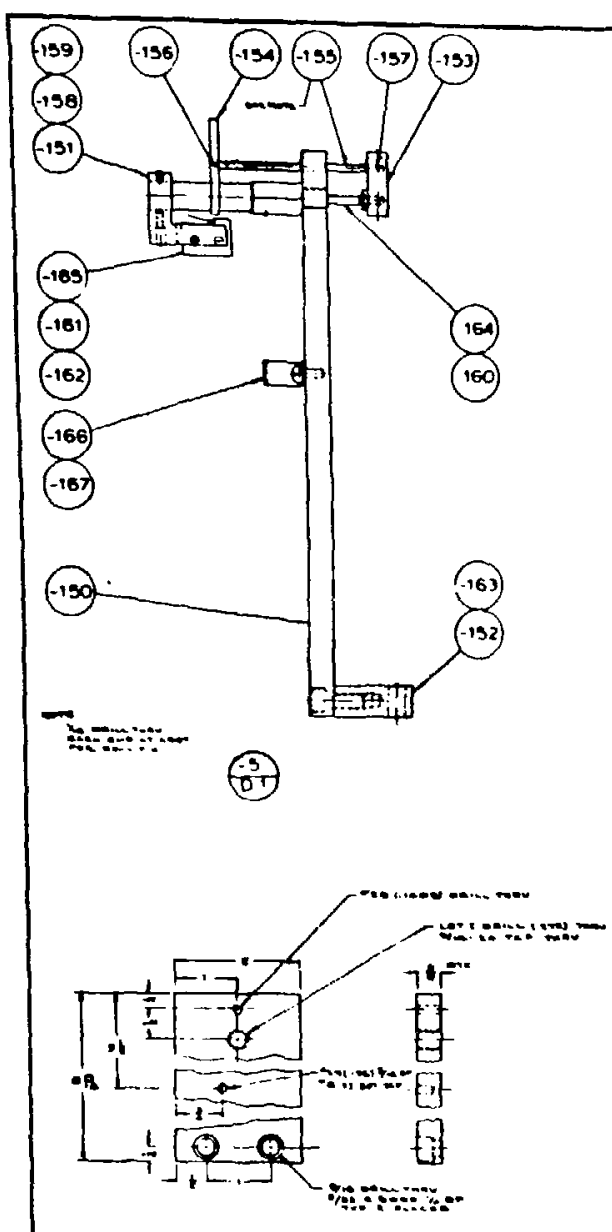

(150)

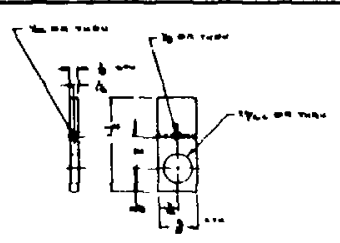

(-154)

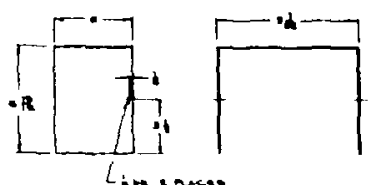

(70.6)

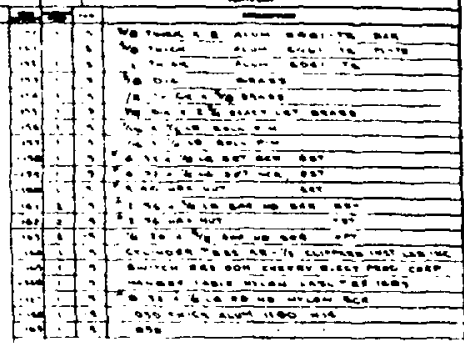

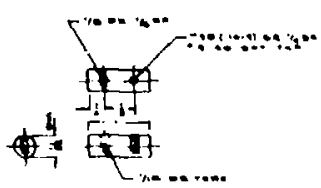

(153)

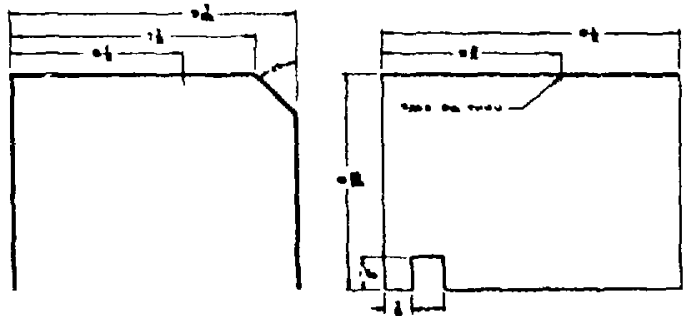

(169)

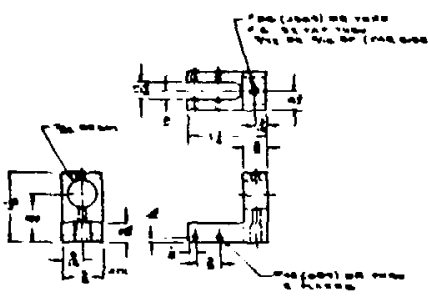

(-151)

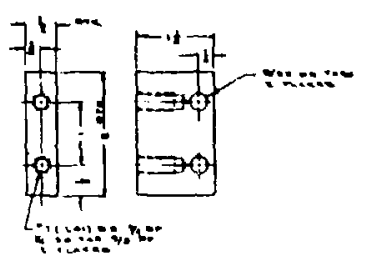

(-152)

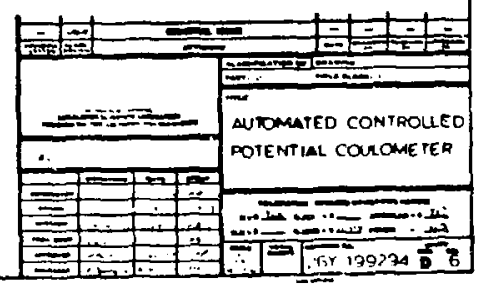

Fig. C-6.

Turntable lock. 


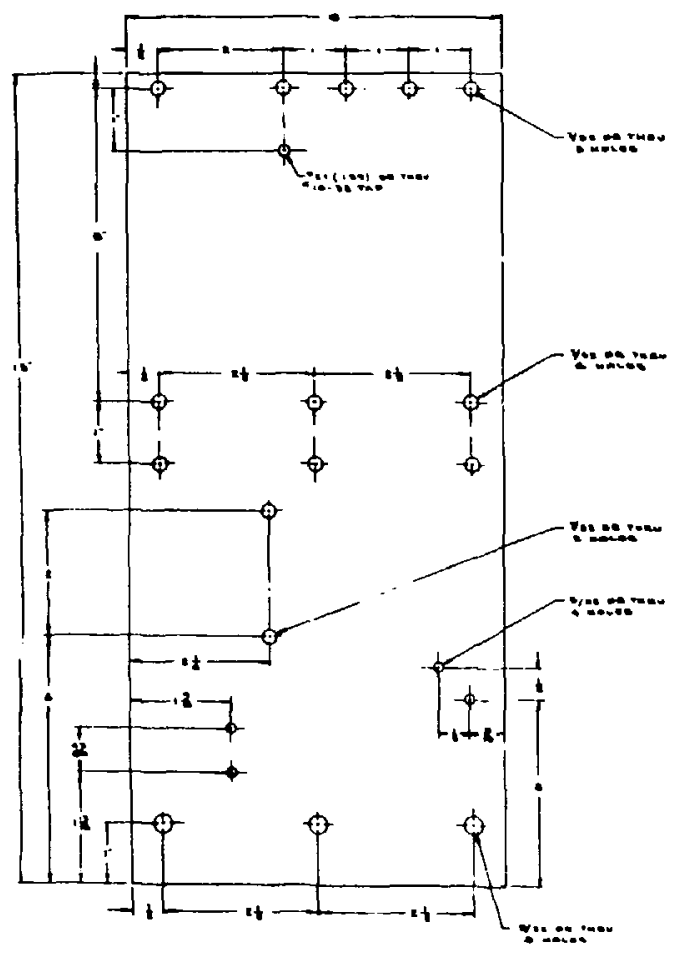

(19)
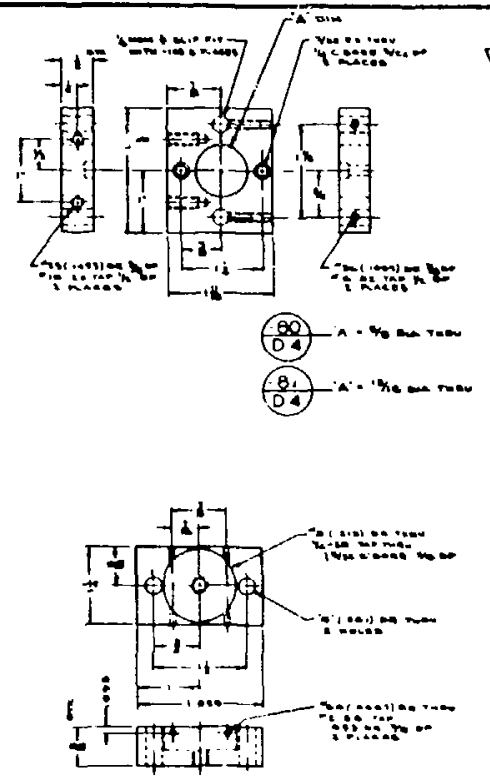

(82)

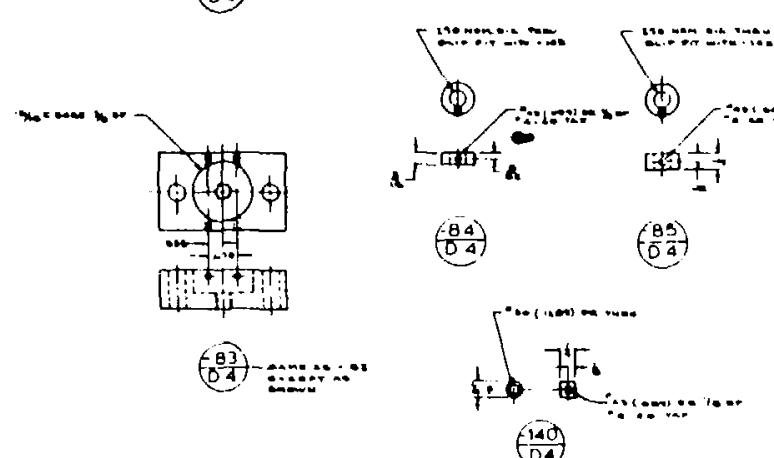

$\left(\frac{100}{104}\right)$

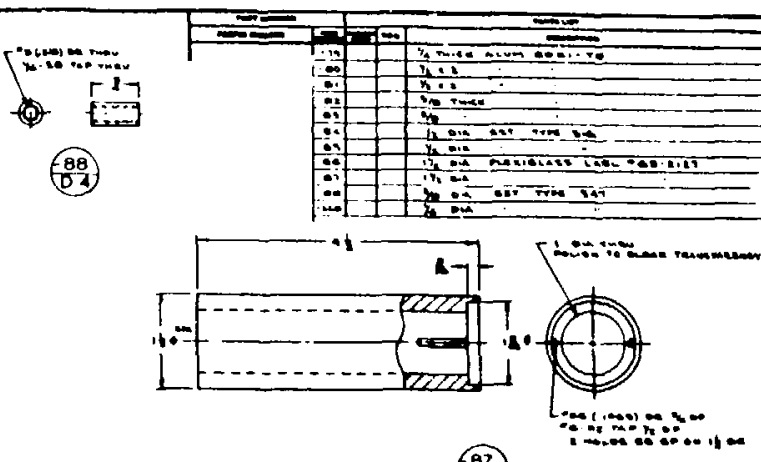

(878)

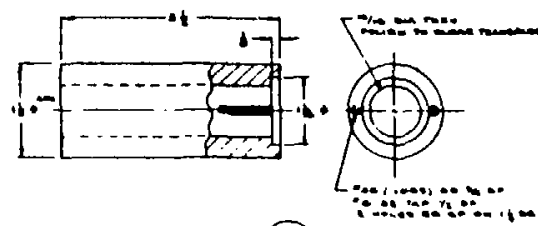

89

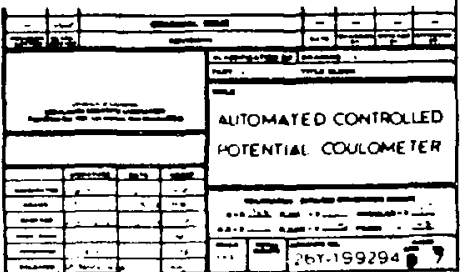




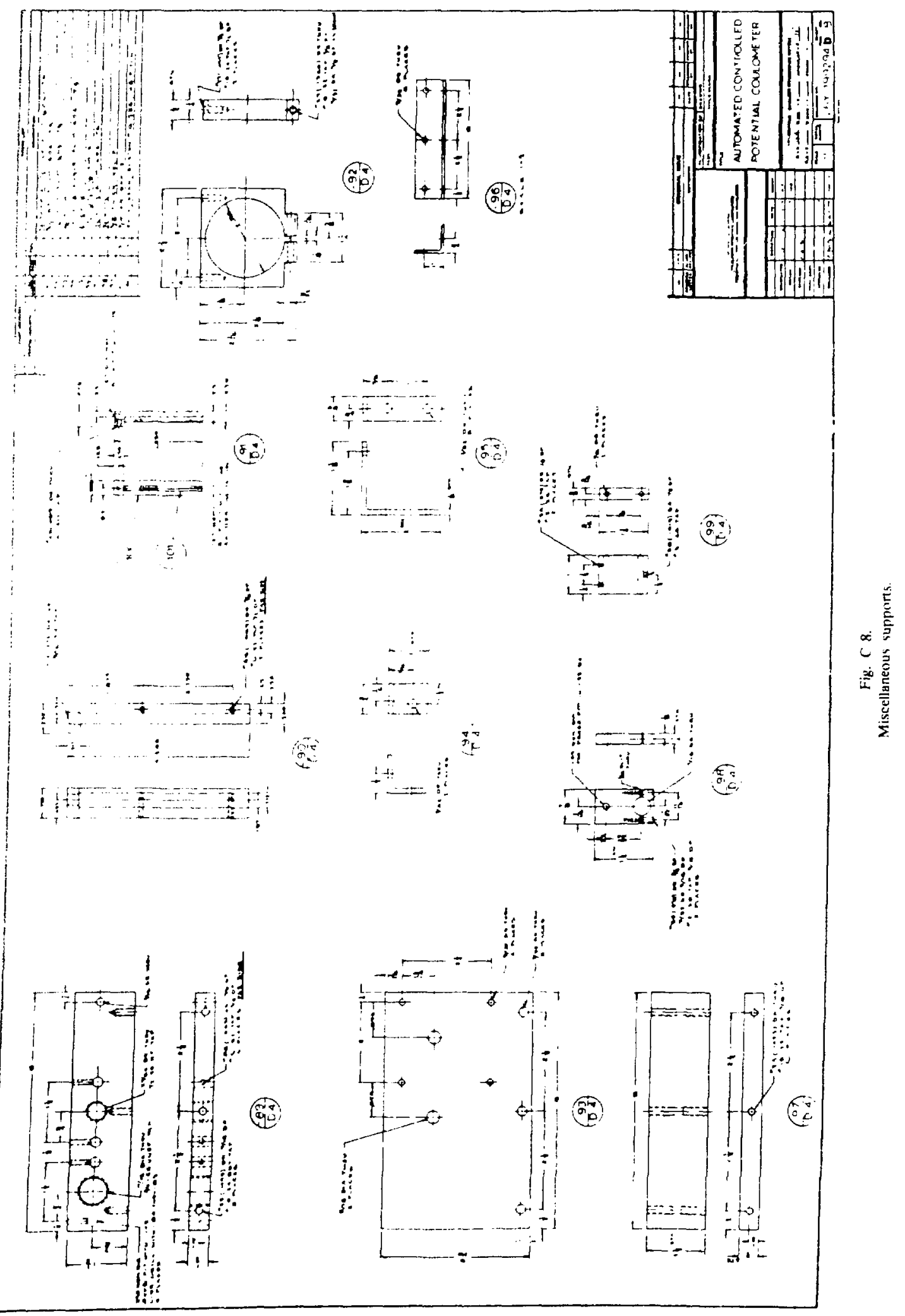




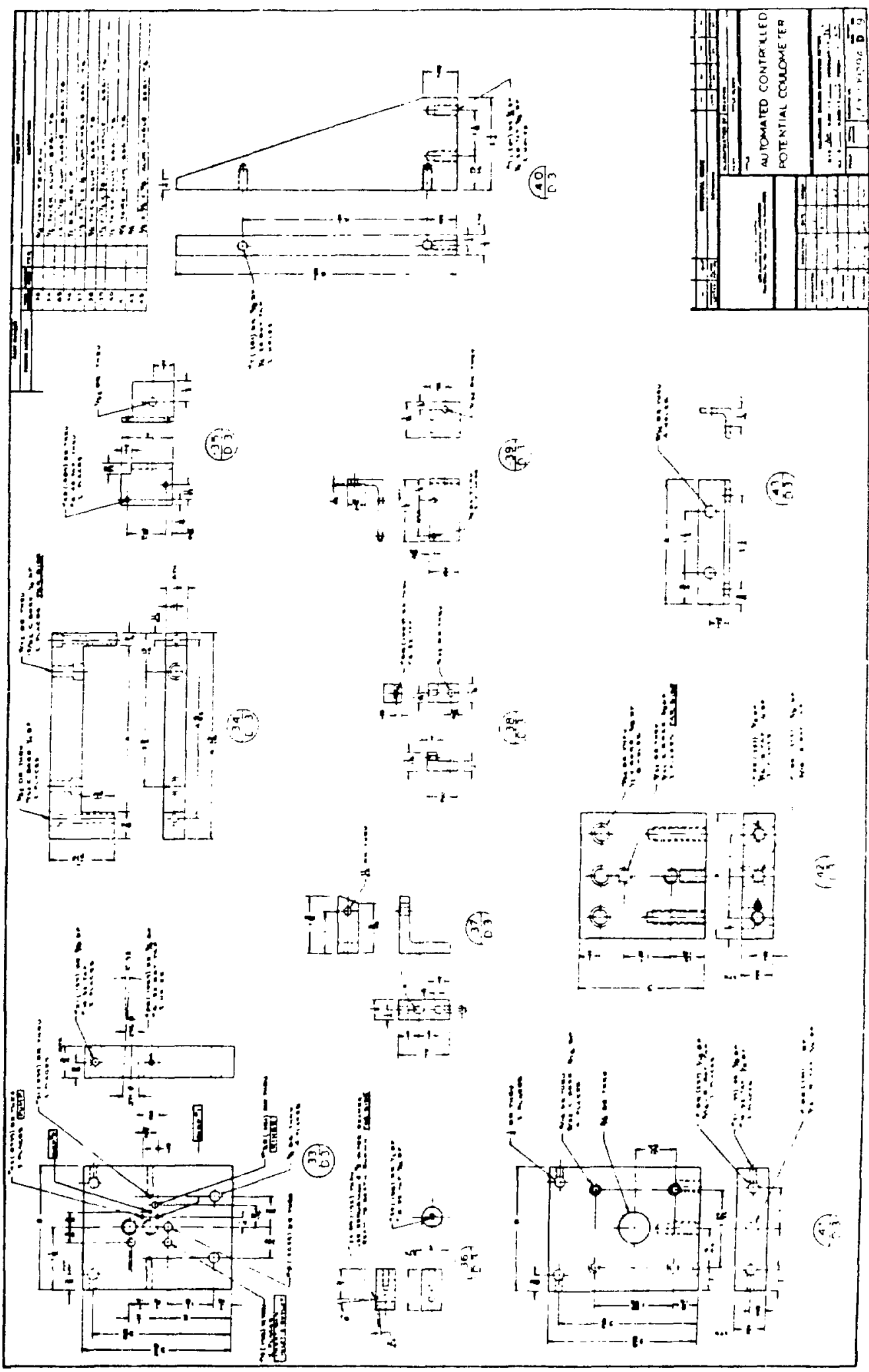

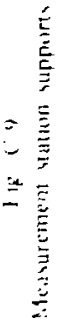



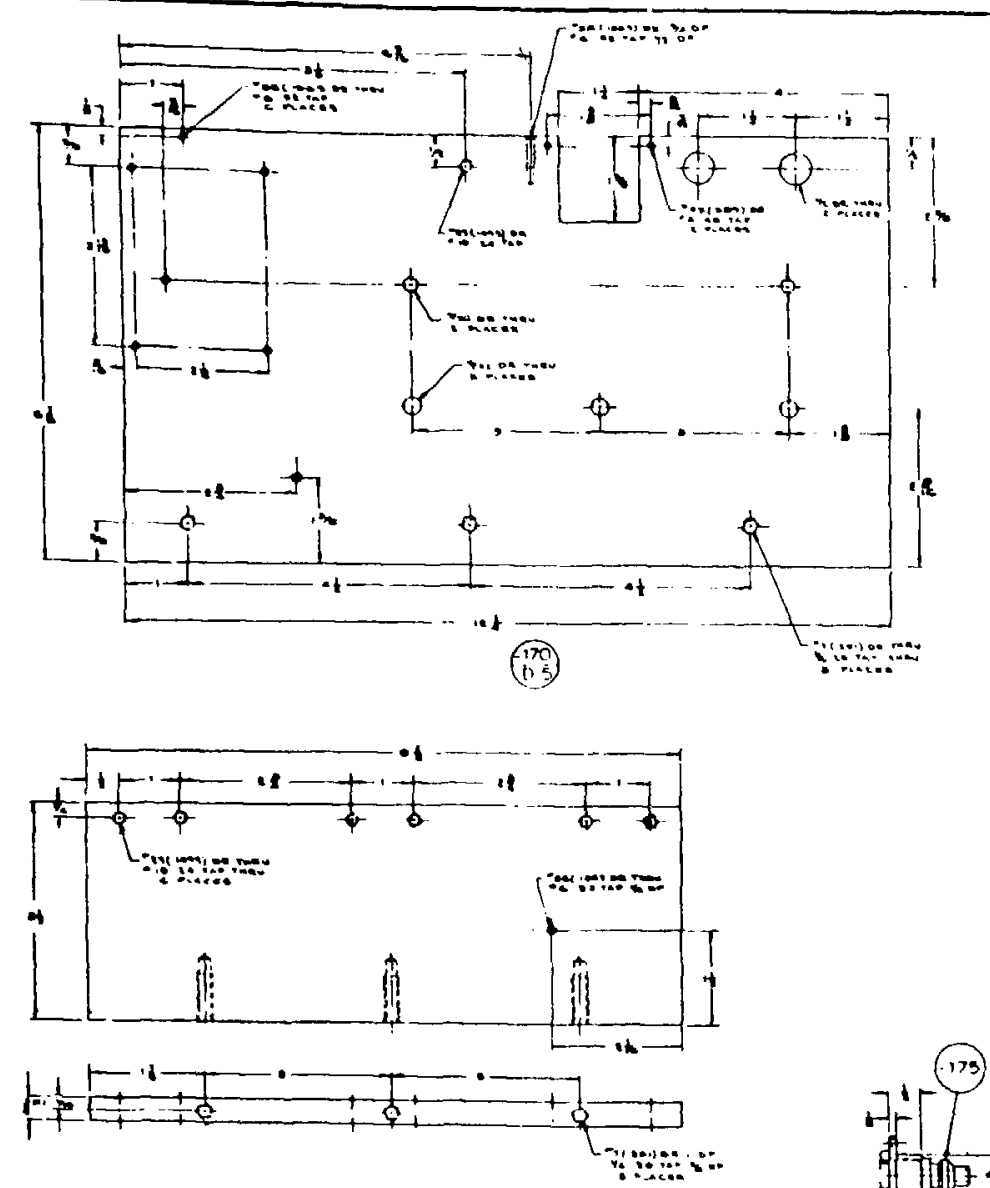

(17)

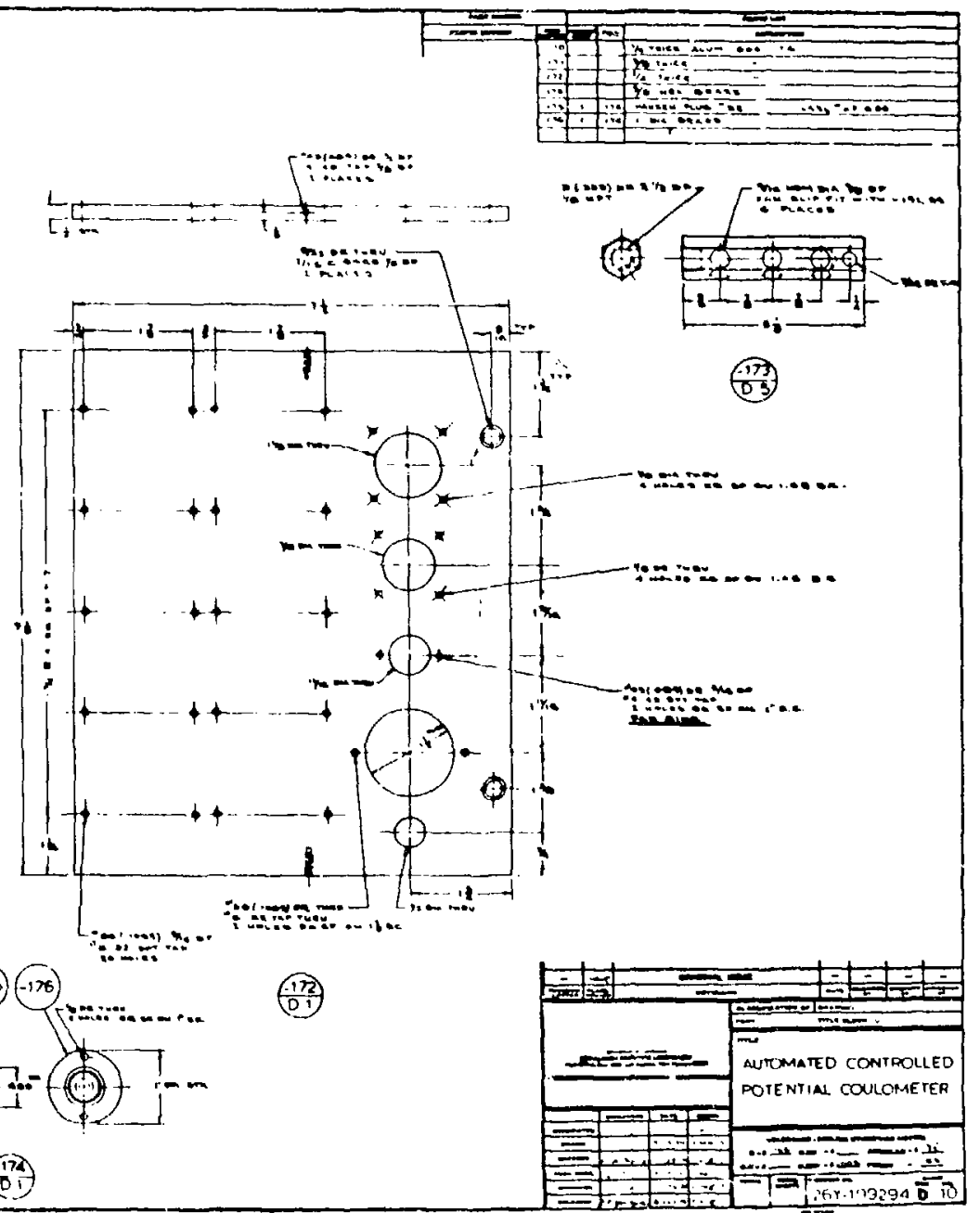

Fig. C. 10

Services support pariel. 


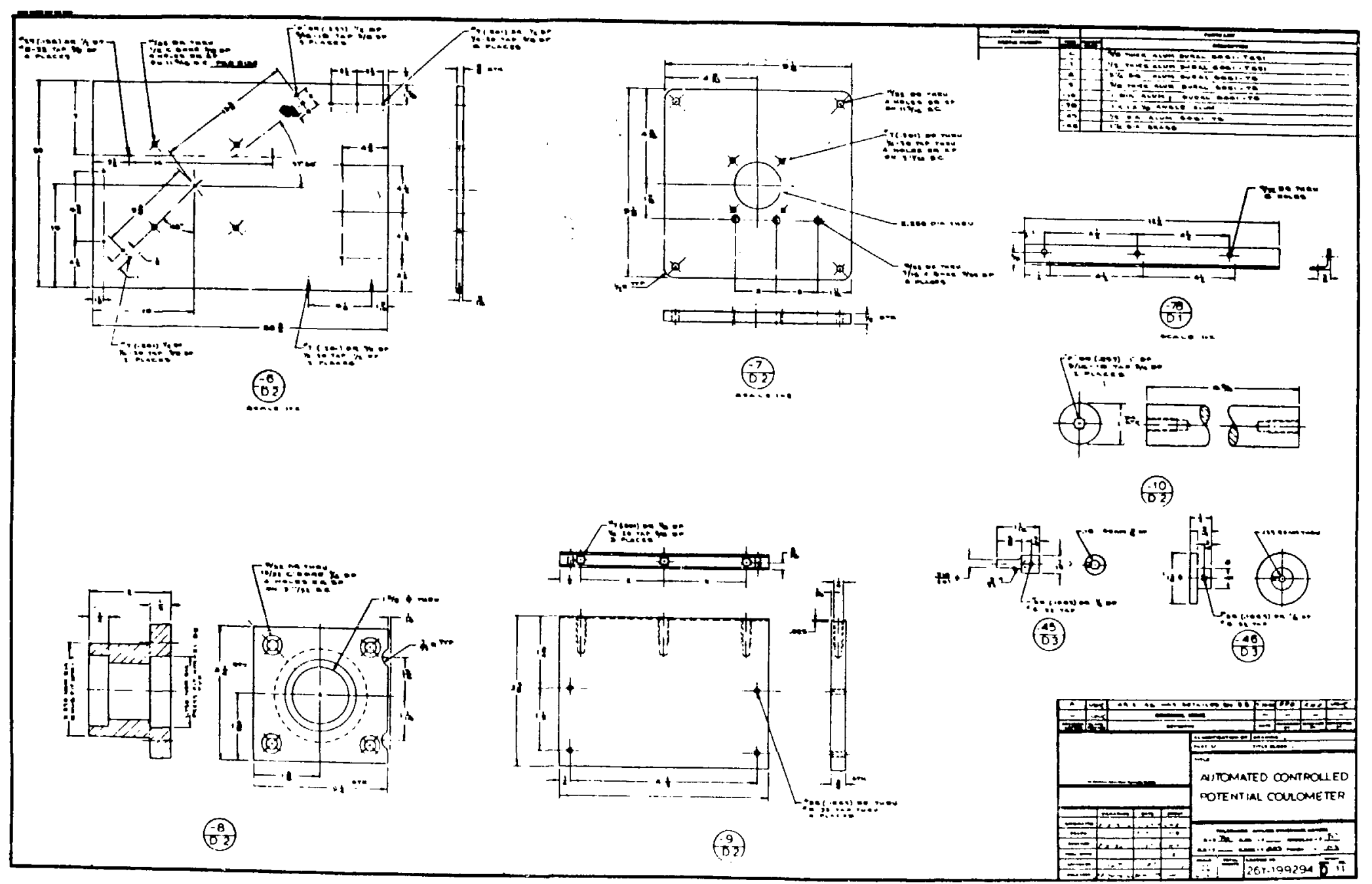

Fig. C II. 


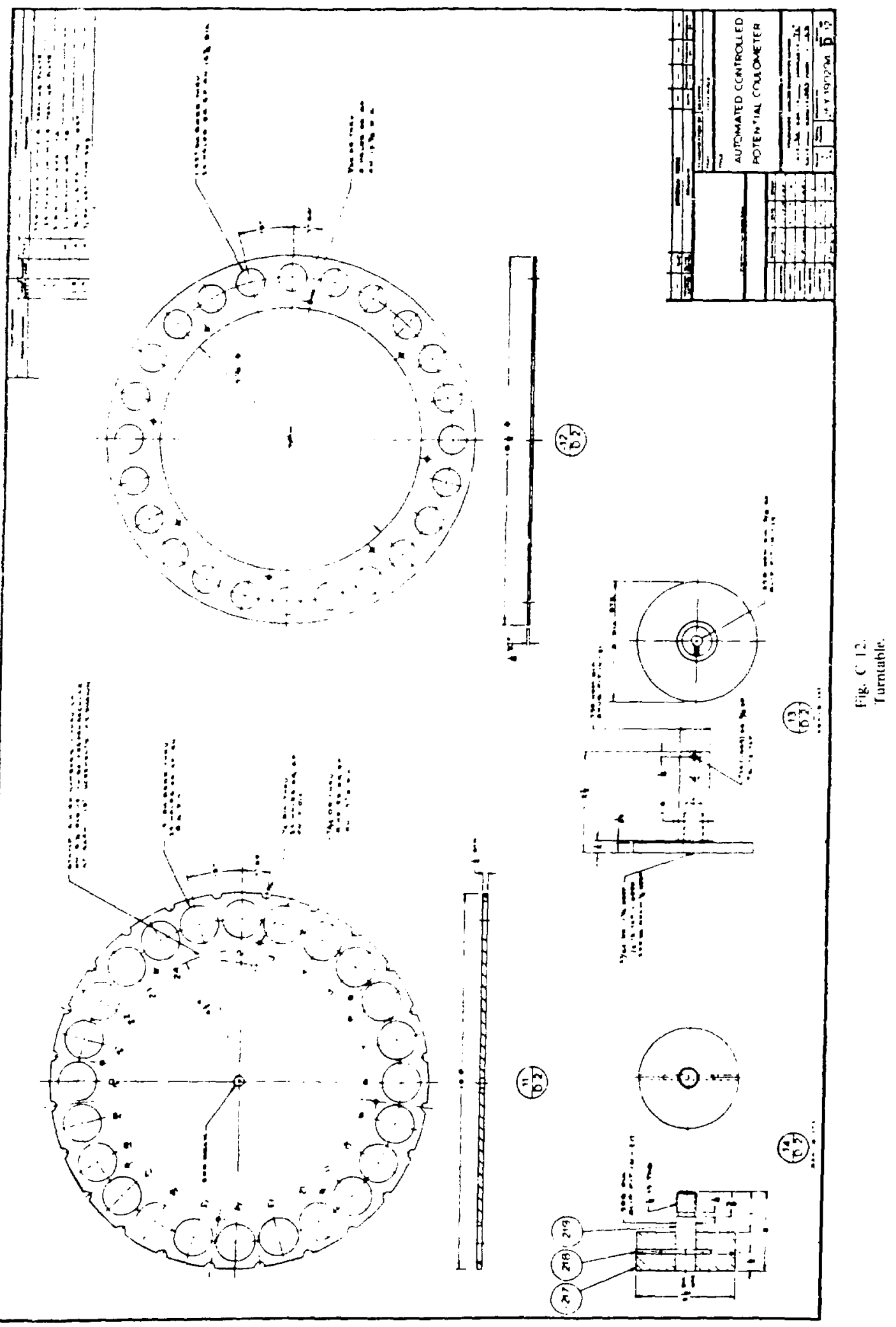




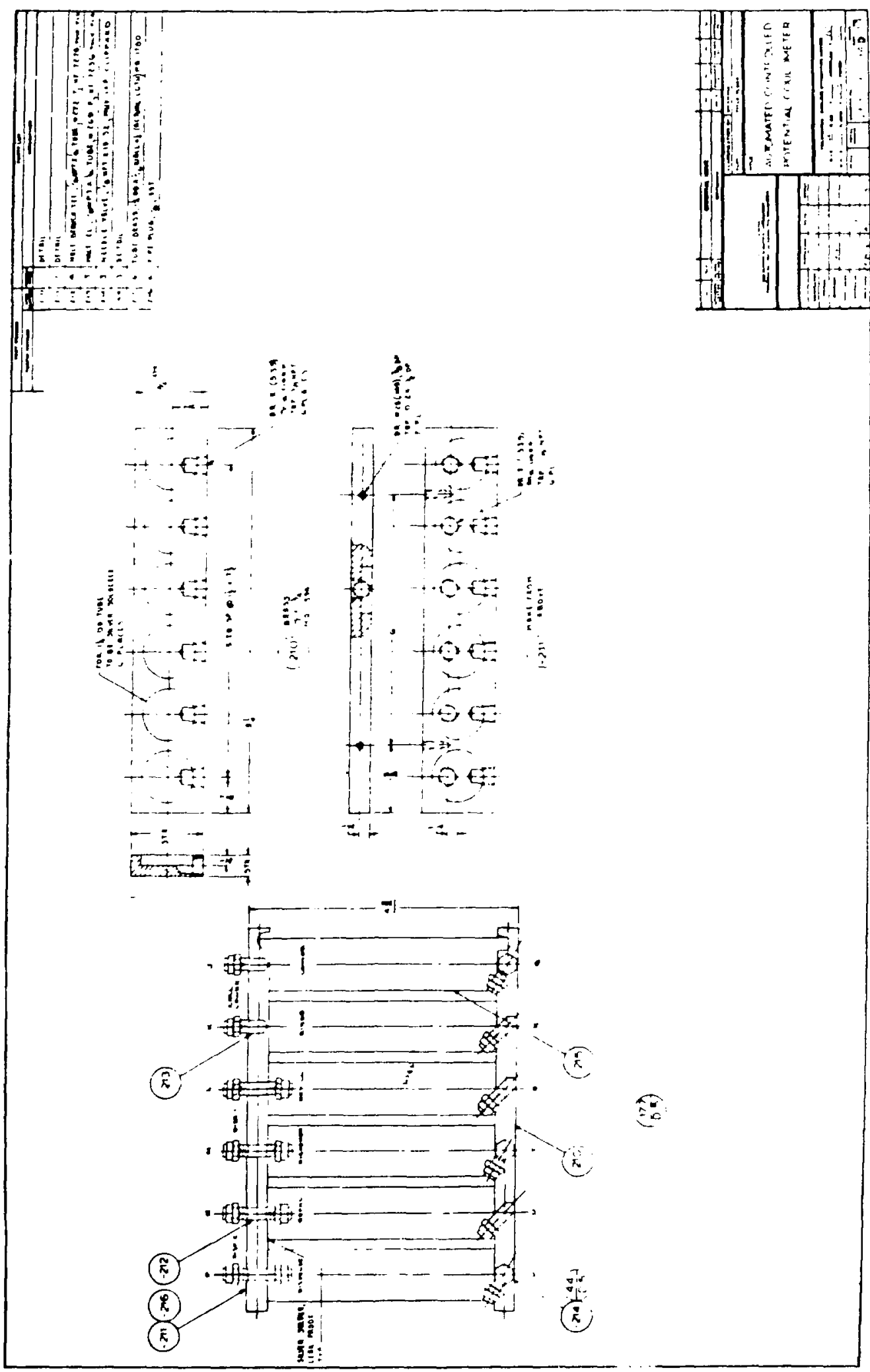




\section{APPENDIX D}

\section{ELECTKICAL CIRCUITP.Y}

Appendix 1 , consises of reduced cippes of cetails of elcetrical componente moluding corcun diagrans for the atstemilted comrolied pusentual coulometer. CAPE package number 2669. which consists of working draw ings. mas be purchas:d from the Teclinical Information Center. Oak Ridge. TN $37 \times 30$. 


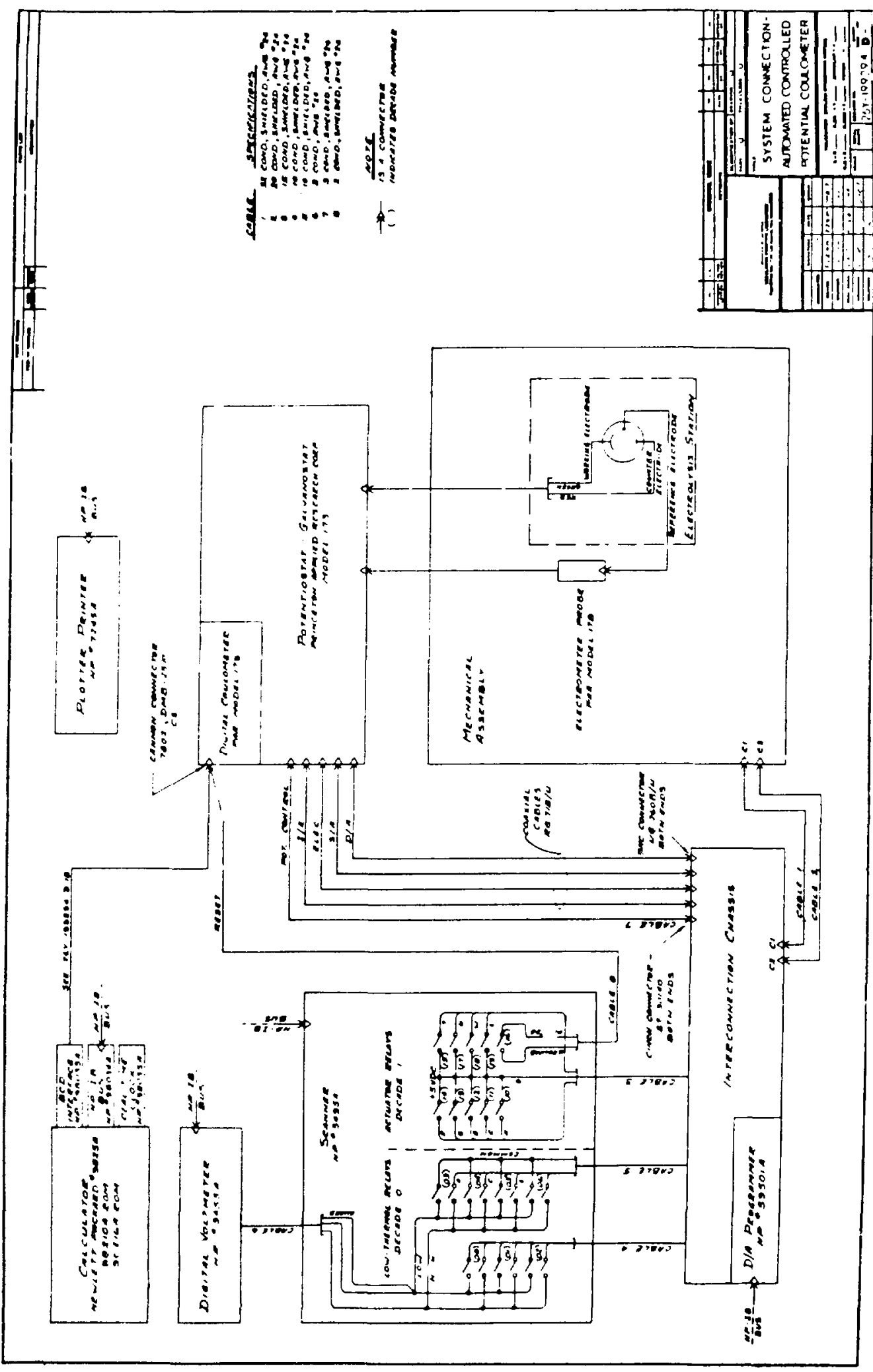

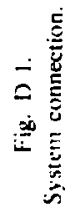




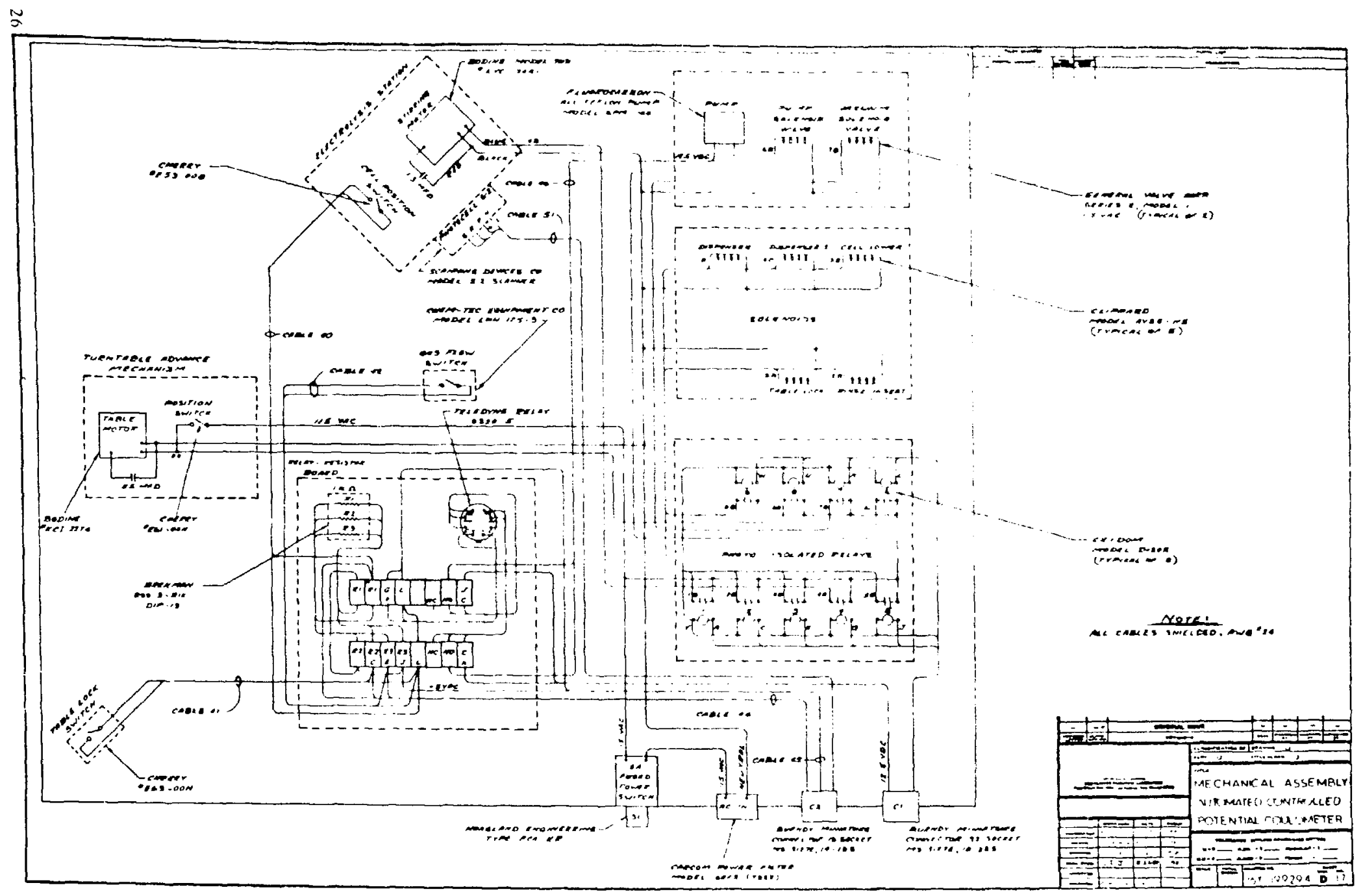

Fig. D 2.

Wiring diagram. 


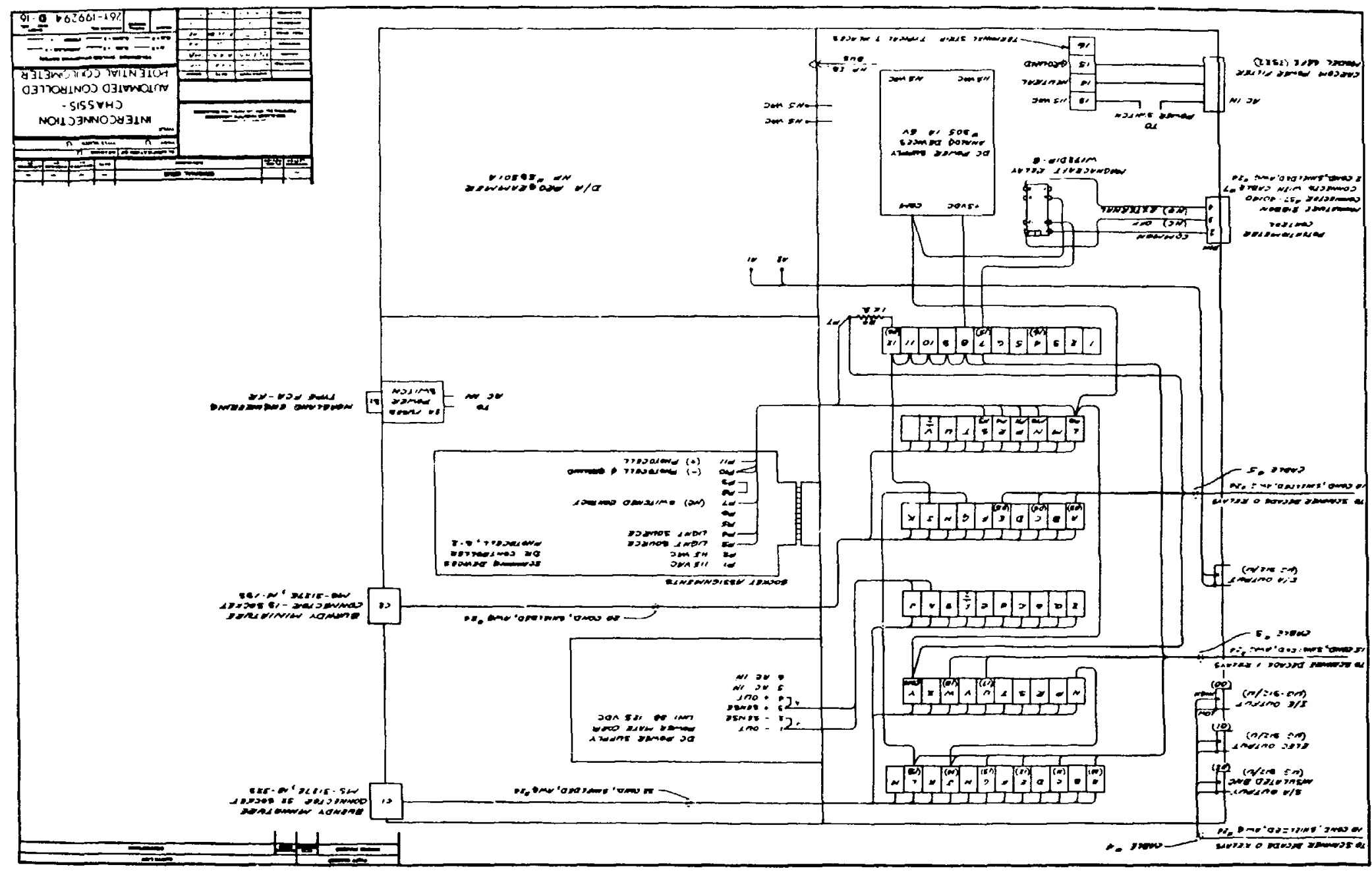



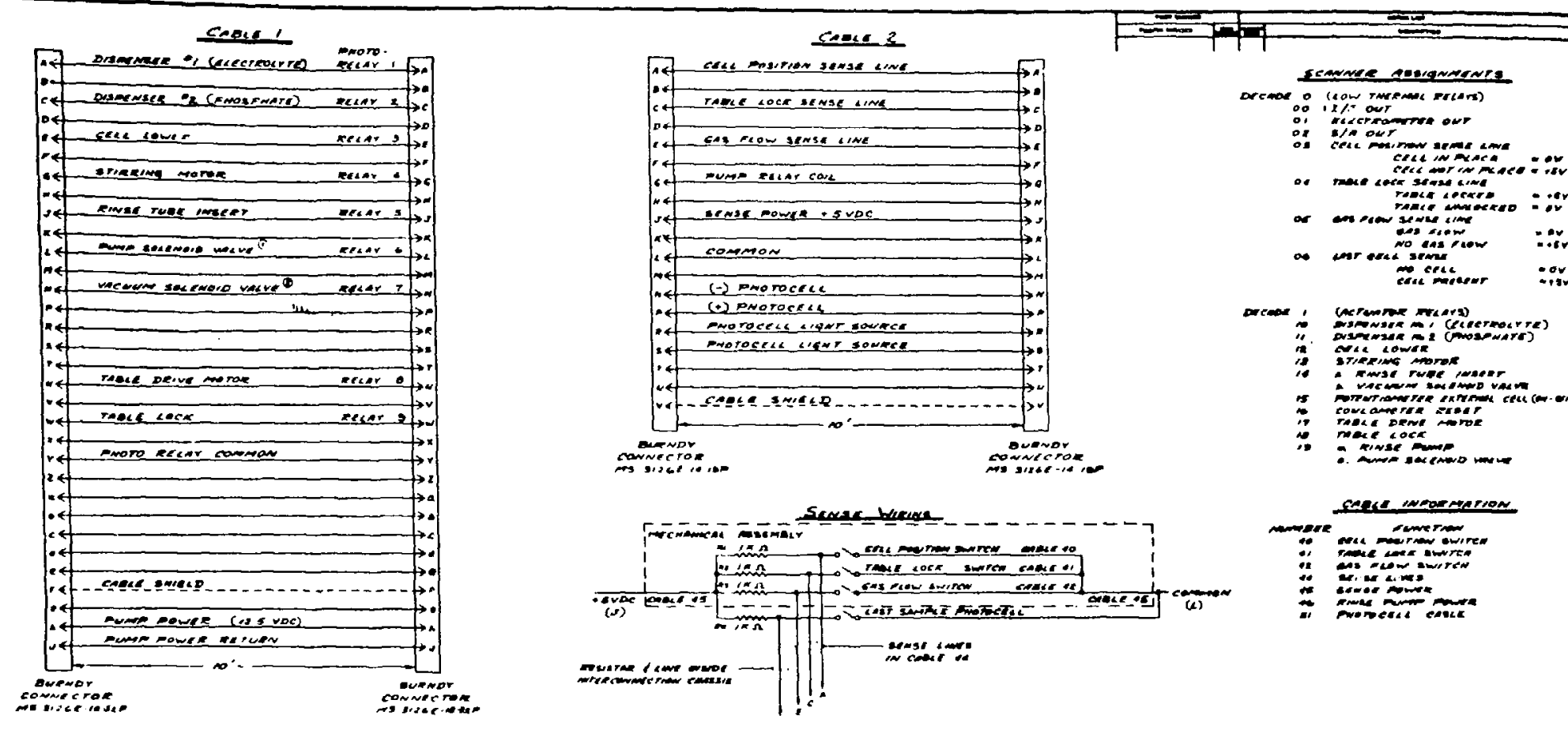

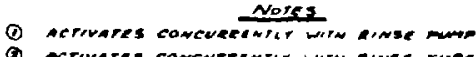

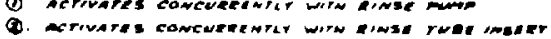

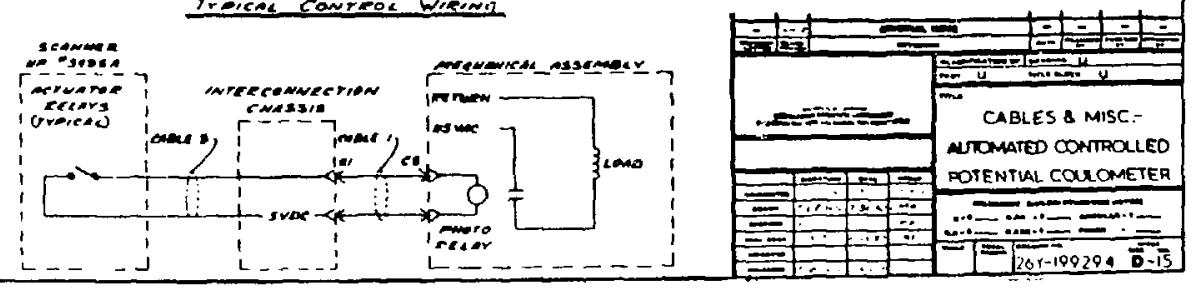

Fig. D.4.
Cables. 


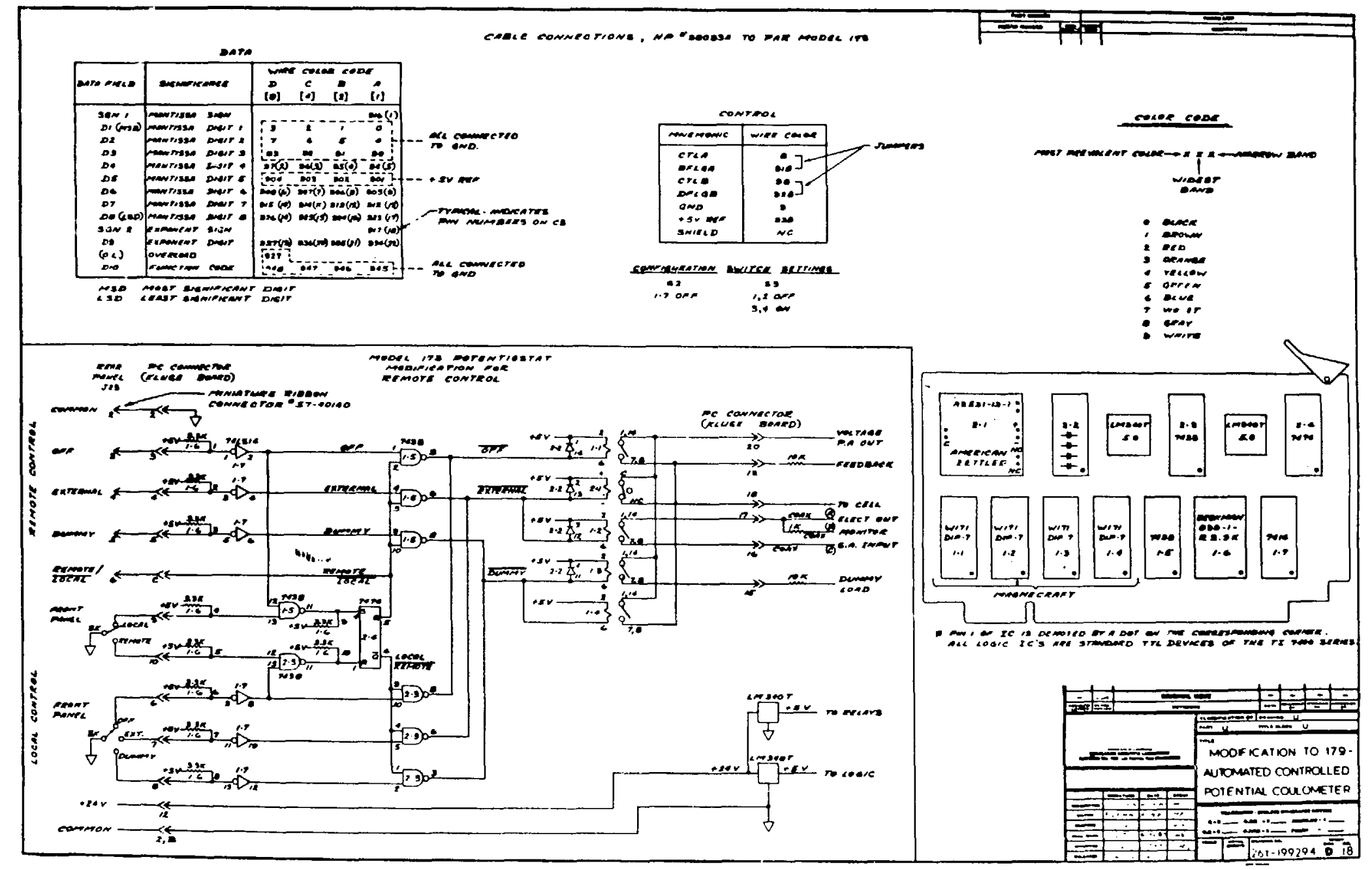




\section{APPENDIX E}

\section{SYSTEM SOFTWARE}

Appendix E consists of system software for the automated controlled-potential coulometer. 

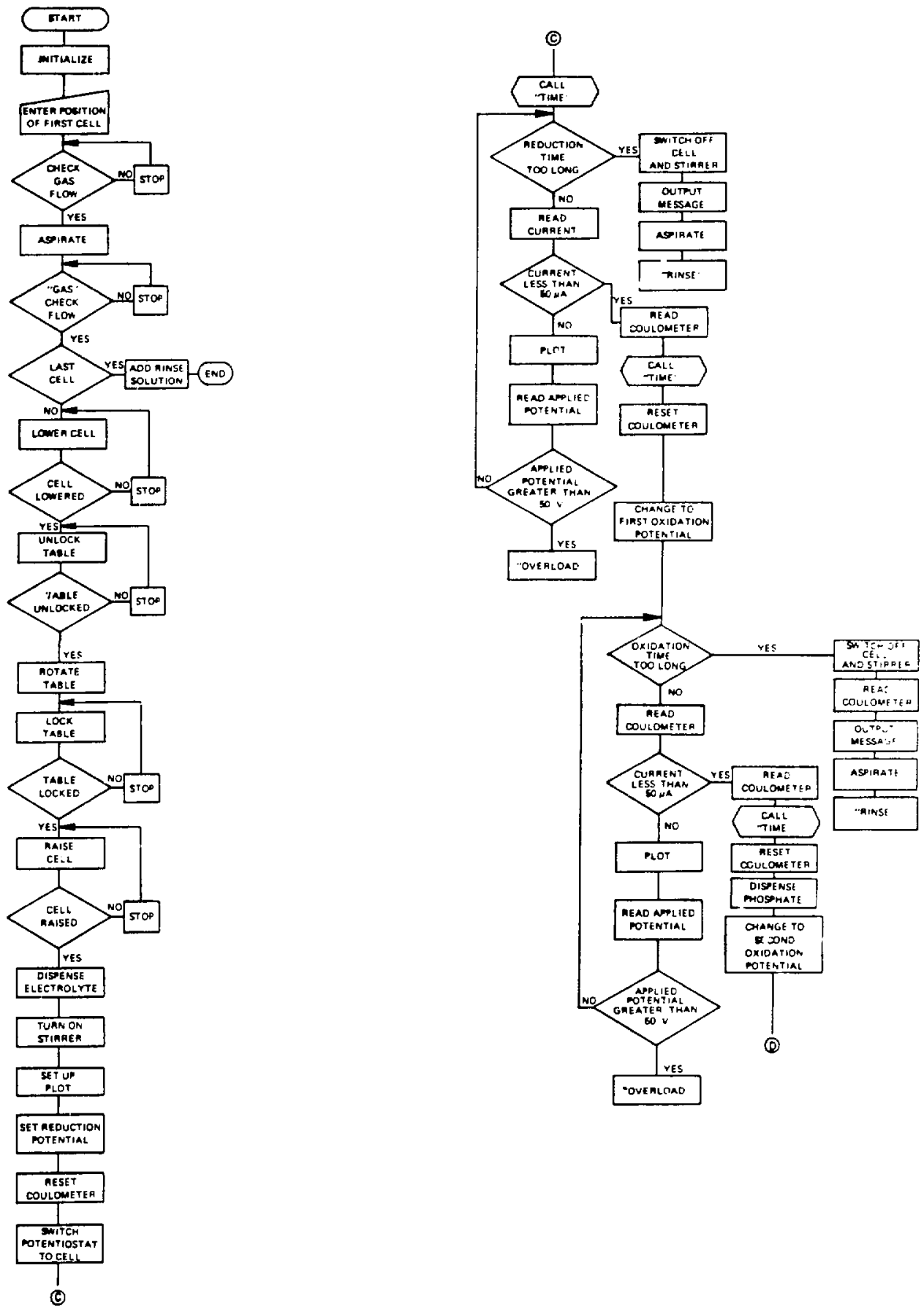

Fig. E-1.

Sample program flow diagram. 

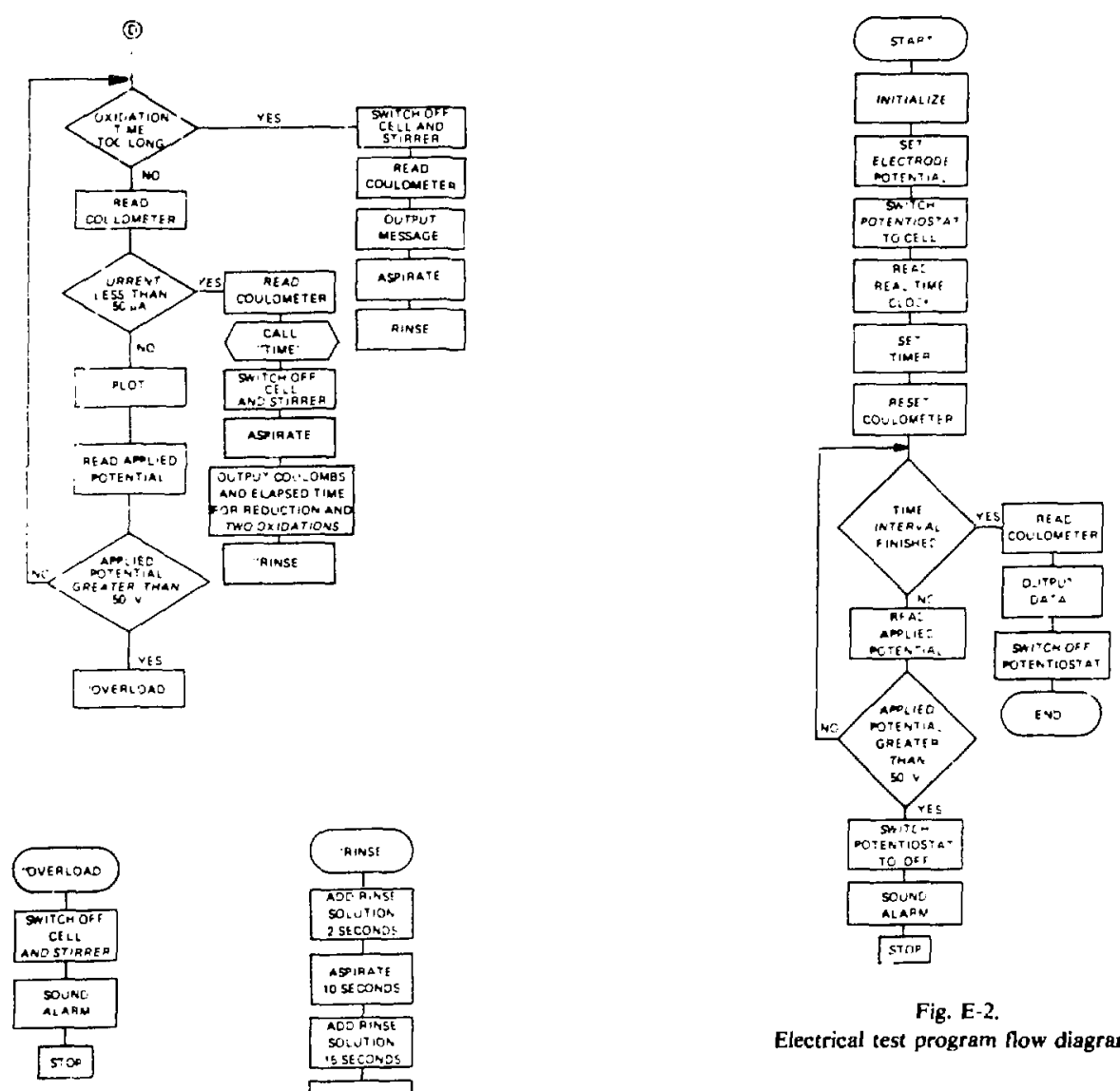

Fig. E-2.

Electrical test program fow diagram.

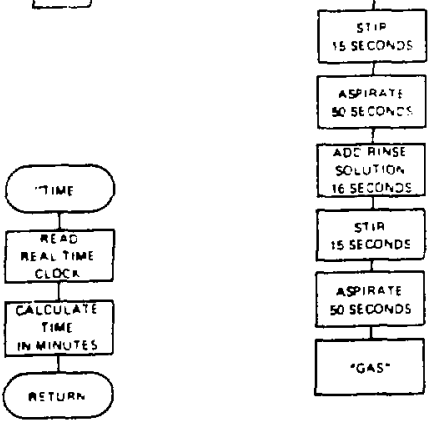

Fig. E-1. (cont) 

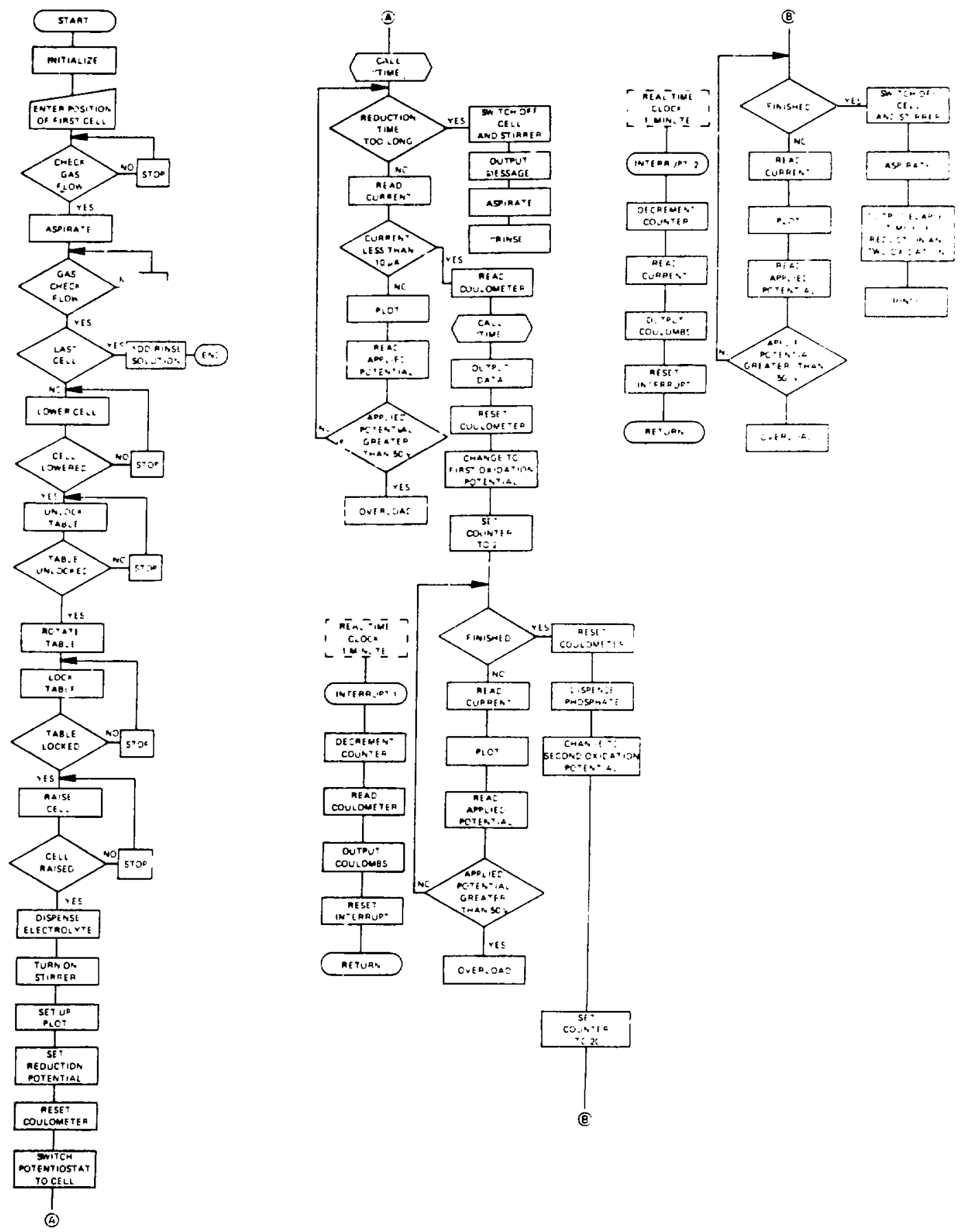

Fig. E-3.

Blank program flow diagram. 
TABLE E:

\section{SPECIAL FUNCTION KEYS LISTING}

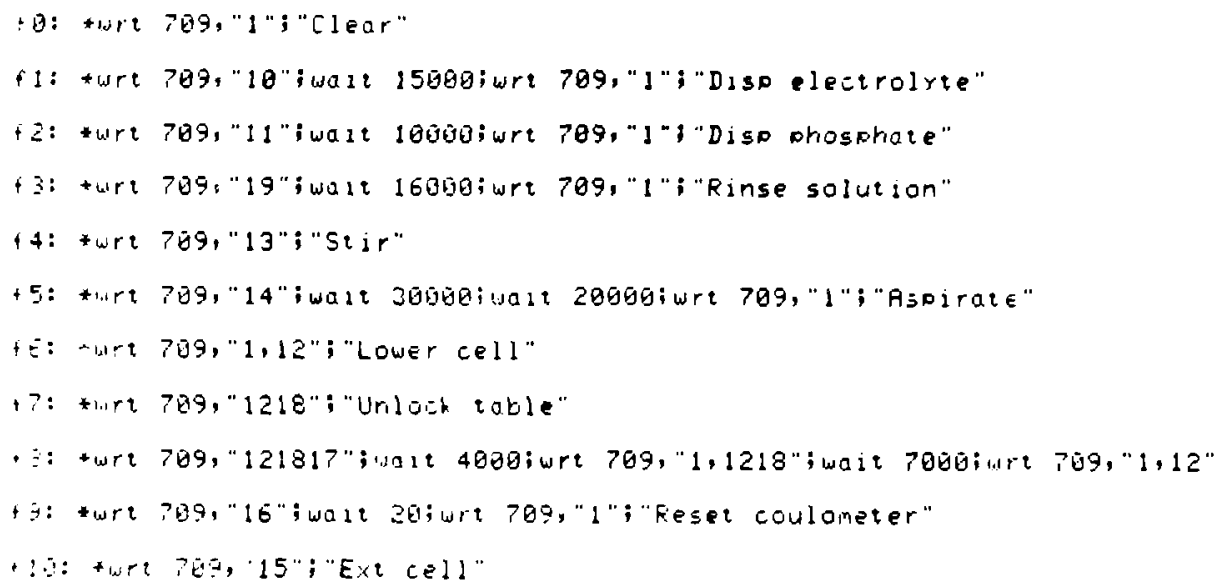

TABLE E II

\section{ELECTRICAL TEST PROGRAM LISTING}

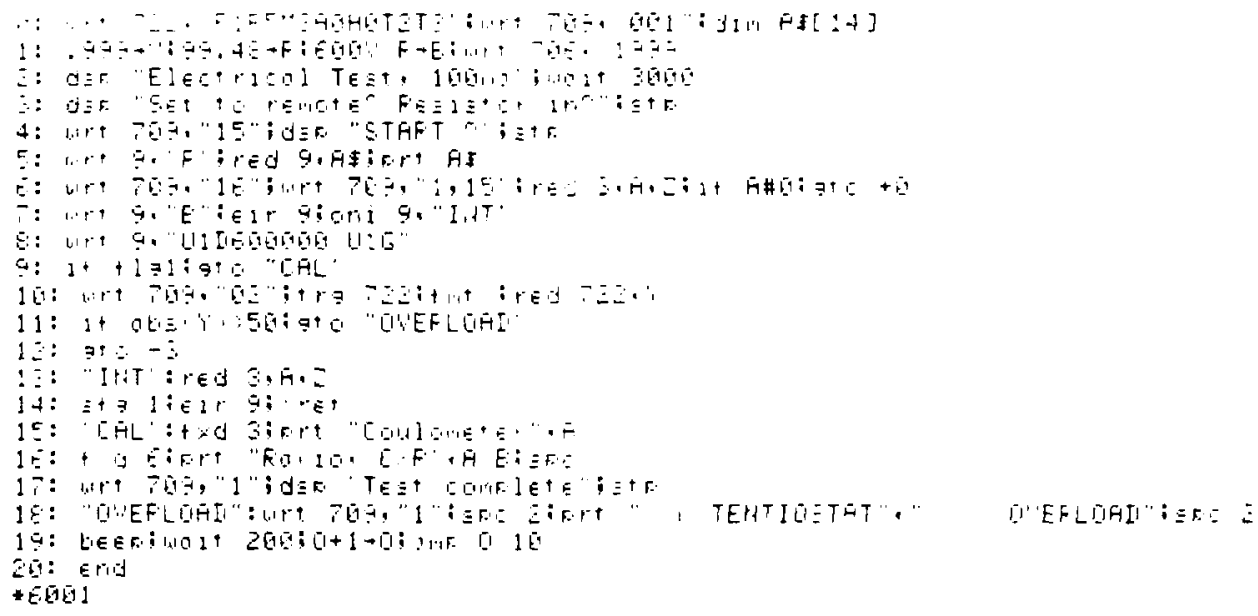




\section{TABLE E-III}

\section{BLANK PROGRAM LISTING}

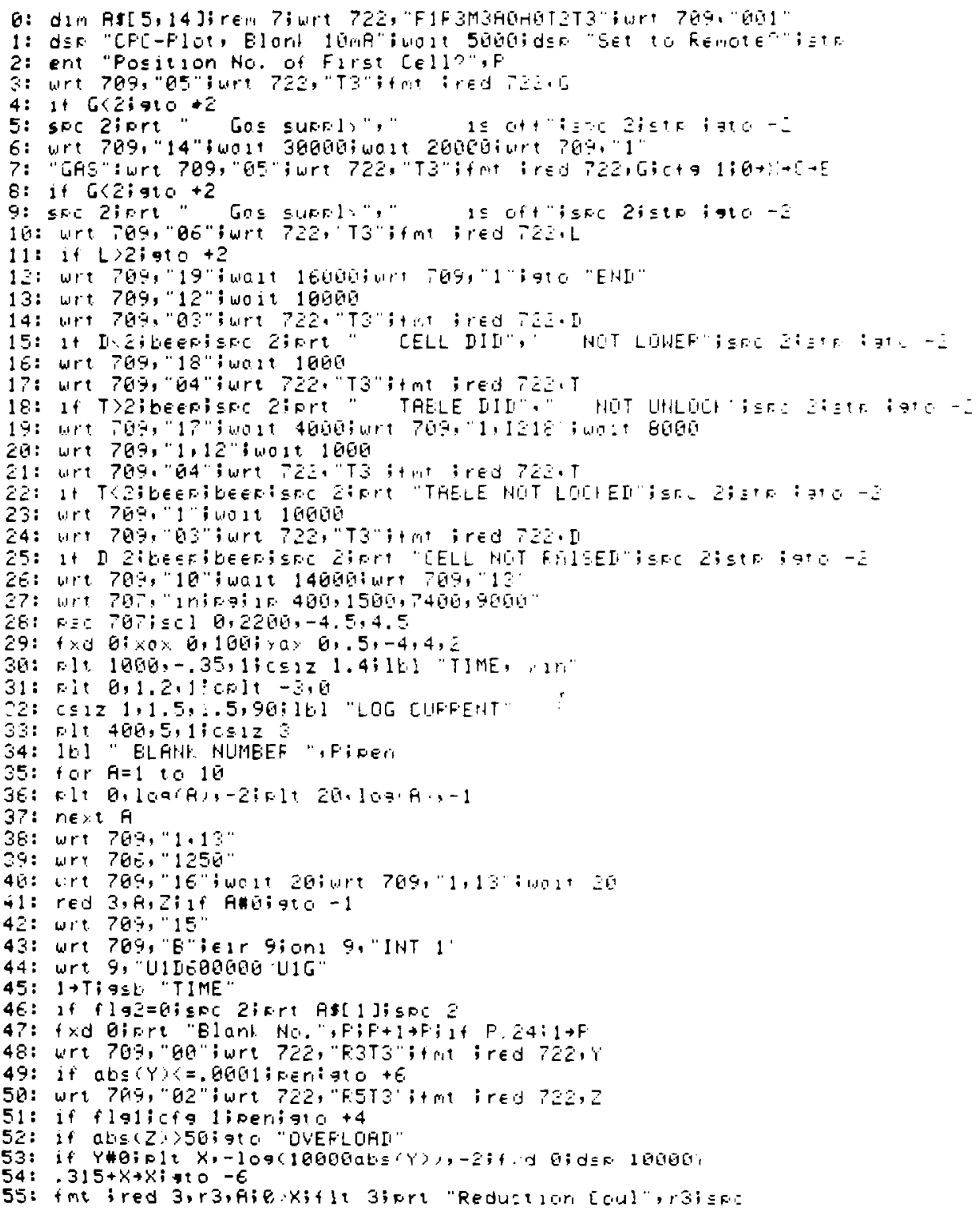


TABLE E-II! (CONT)

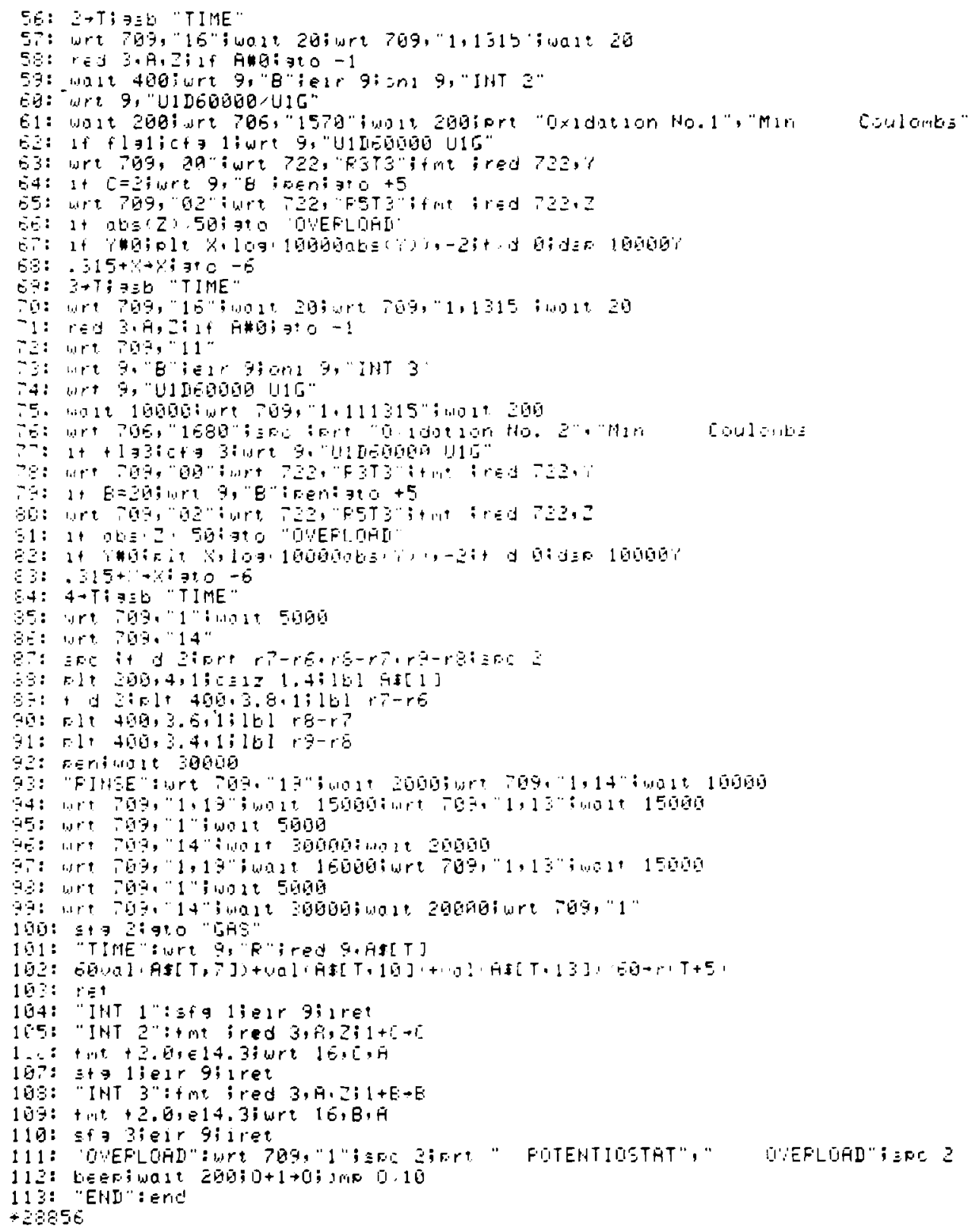


TABLE E-IV

\section{SAMPLE PROGRAM LISTING}

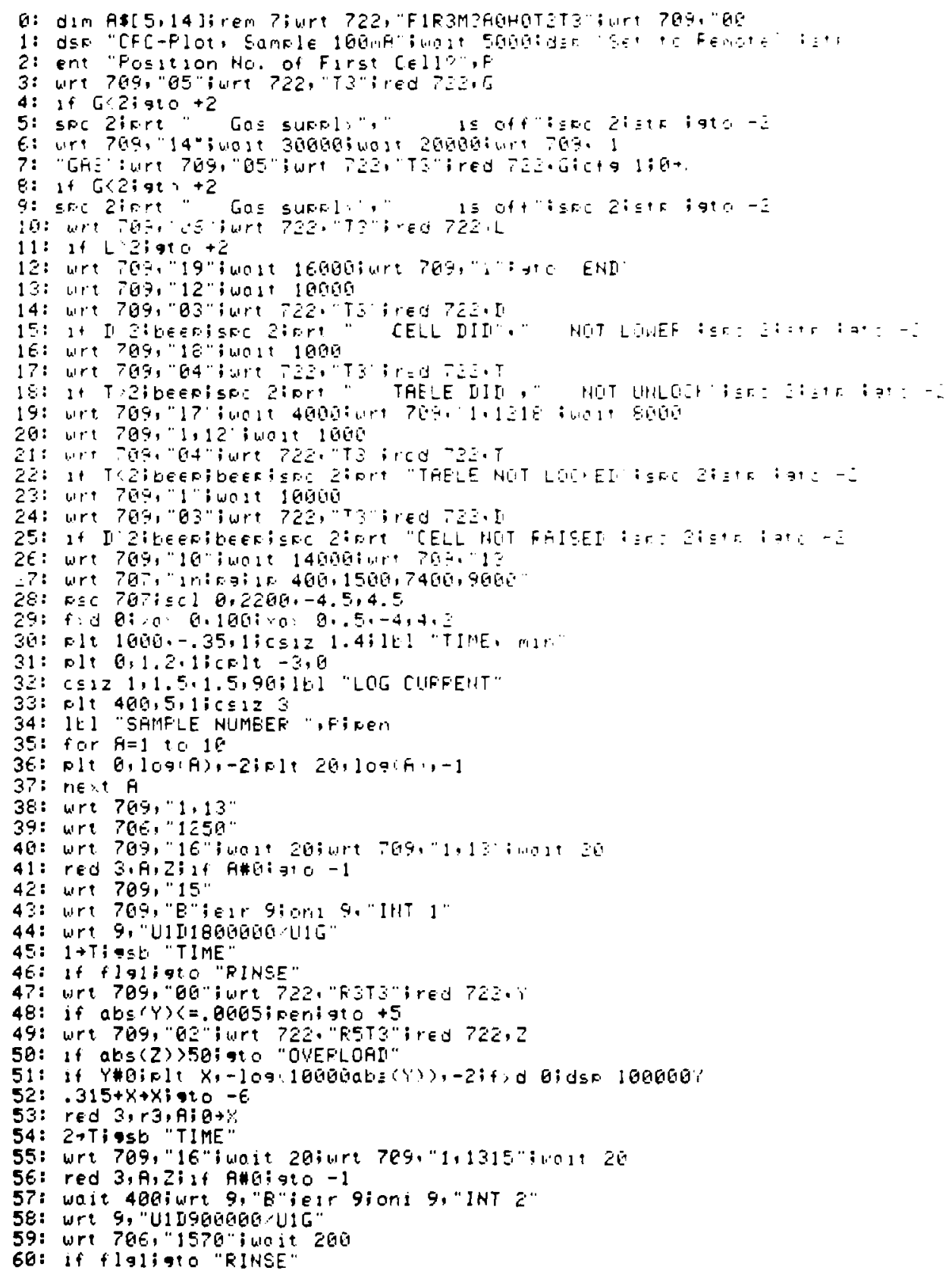


TABLE EIV (CONT)

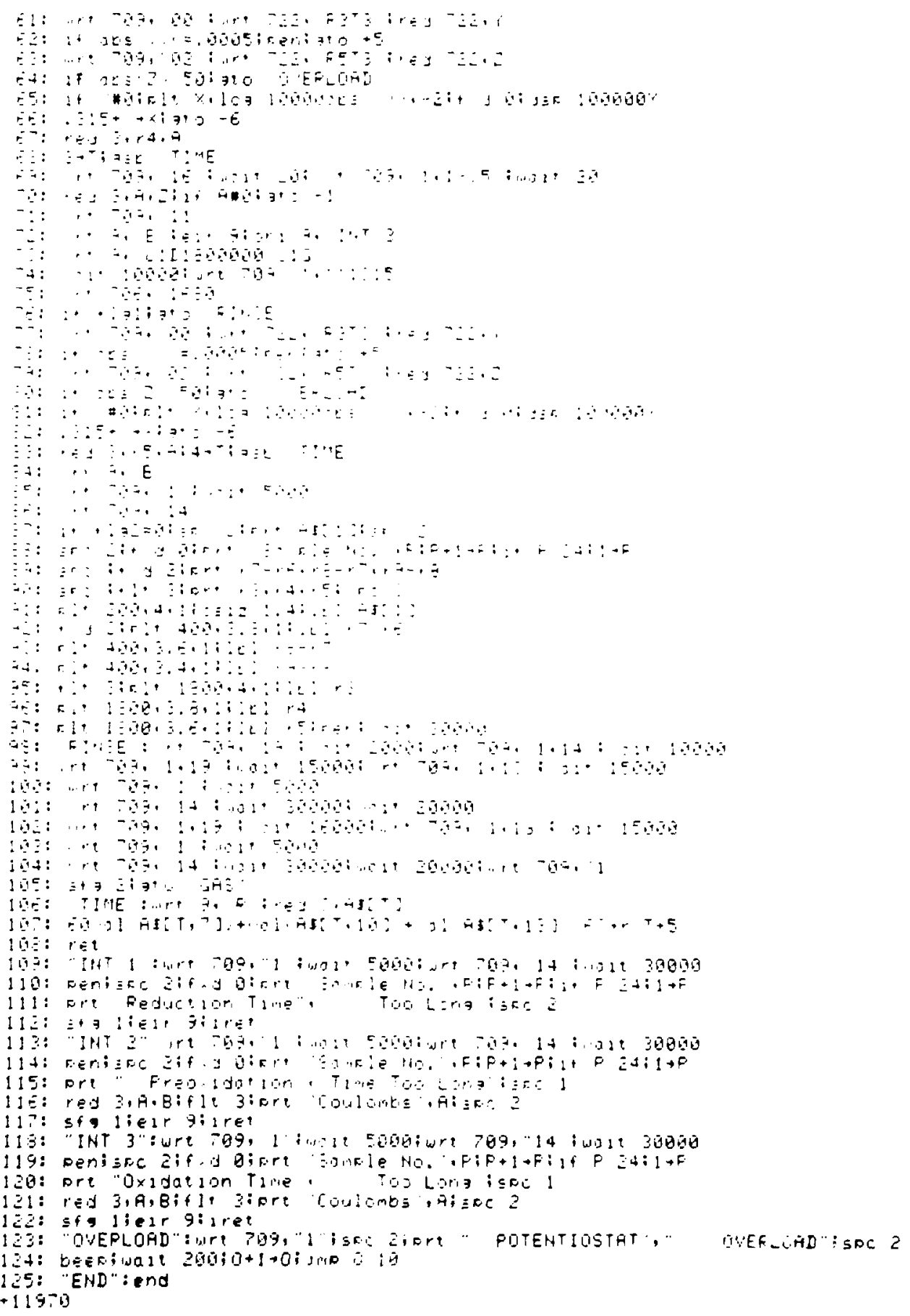




\section{REFERENCES}

1. D. D. Jackson. D. J. Hodgkins, R. M. Hollen. and J. E. Rein. "Automated Spectrophotometer for Plutonium and Uranium Determination." Los Alamos National Laboratory report LA 6091 (February 1976).

2. G. R. Waterbury. Comp.. “Analytical Methods for Fissionable Materia! Determinations in the Nuclear Fuel Cycle. Octuber 1. 1977 ... September 30. 1478." Los Alamos National Laboratory report LA 7553 PR (January 1979).
3. S. F. Marsh. "Extraction Spectrophorometric Deter mination of Microgram Quantities of Cranium wath Beneoyltriflueroacetone." Anal. Chum. Acta 105. $4.34 .443(1479)$.

4. D. D. Jackson. R. M. Hollen. F. R. Ruemsch, and J. F. Rein. "Controlled Potential (oulometric Deter mination of Plutonium with a Hydrocnloric Acid Sulfamic Acid Flectrolyte and Phosphate Complex ing." Anal. Chim. Acta 117, 205 215 1148011. 